\title{
Differential effects of monensin and a blend of essential oils on rumen microbiota composition of transition dairy cows
}

\author{
M. Schären, ${ }^{*}$ C. Drong, ${ }^{*}$ K. Kiri,† S. Riede,† M. Gardener,‡ U. Meyer, ${ }^{* 1}$ J. Hummel,§ T. Urich,\# G. Breves,† \\ and S. Dänicke* \\ *Institute of Animal Nutrition, Friedrich-Loeffler-Institute (FLI), Federal Research Institute for Animal Health, Bundesallee 50, 38116 Brunswick, \\ Germany \\ †Department of Physiology, University of Veterinary Medicine Hanover, Bischofsholer Damm 15, 30173 Hanover, Germany \\ ‡Environment, Earth and Ecosystems, The Open University, Milton Keynes, MK7 6AA, United Kingdom \\ §Ruminant Nutrition, Department of Animal Sciences, Faculty of Agricultural Sciences, Georg-August University Göttingen, Kellnerweg 6, \\ 37077 Göttingen, Germany \\ \#Institute of Microbiology, University of Greifswald, Friedrich-Ludwig-Jahn-Str. 15, 17489 Greifswald, Germany
}

\begin{abstract}
In response to oral application, monensin alters the rumen microbiota, increasing ruminal propionate production and energy availability in the animal. Data from different studies indicate that the susceptibility of rumen bacteria to monensin is mainly cell-wall dependent but tracing its activity to specific microbial groups has been challenging. Several studies have shown a similar effect for essential oils but results are inconsistent. To investigate the influence of monensin and a blend of essential oils (BEO, containing thymol, guaiacol, eugenol, vanillin, salicylaldehyde, and limonene) on the rumen microbiome, rumen liquid samples were collected orally on d 56 postpartum from cows that had either received a monensin controlled-release capsule 3 wk antepartum, a diet containing a BEO from 3 wk antepartum onward, or a control diet $(\mathrm{n}=12)$. The samples were analyzed for $\mathrm{pH}$, volatile fatty acid, ammonia, and lipopolysaccharide concentrations and protozoal counts. A 16S rRNA gene fingerprinting analysis (PCR-singlestrand conformation polymorphism) and sequencing revealed that the BEO treatment had no effect on the rumen microbiota, whereas monensin decreased bacterial diversity. Twenty-three bacterial species-level operational taxonomic units were identified for which monensin caused a significant decrease in their relative abundance, all belonging to the phyla Bacteroidetes (uncultured BS11 gut group and BS9 gut group) and Firmicutes (Lachnospiraceae, Ruminococcaceae, and Erysipelotrichaceae). Ten bacterial operational taxonomic units belonging to the phyla Actinobacteria ( $\mathrm{Co}$ riobacteriaceae), Bacteroidetes (Prevotella), Cyanobacteria (SHA-109), and Firmicutes (Lachnospiraceae and
\end{abstract}

\footnotetext{
Received September 13, 2016.

Accepted December 14, 2016.

${ }^{1}$ Corresponding author: Ulrich.Meyer@fli.de
}

Ruminococcaceae) increased in relative abundance due to the monensin treatment. These results confirm the hypothesis that varying effects depending on cell-wall constitution and thickness might apply for monensin sensitivity rather than a clear-cut difference between gram-negative and gram-positive bacteria. No effect of monensin on the archaea population was observed, confirming the assumption that reported inhibition of methanogenesis is most likely caused through a decrease in substrate availability, rather than by a direct effect on the methanogens. The data support the hypothesis that the observed increase in ruminal molar propionate proportions due to monensin may be caused by a decrease in abundance of non-producers and moderate producers of propionate and an increase in abundance of succinate and propionate producers.

Key words: rumen microbiota, monensin, essential oils, sequencing

\section{INTRODUCTION}

At the onset of lactation, a dairy cow's metabolism is confronted with a massive increase in energy demand that cannot be met by a simultaneous increase in feed intake. Therefore, physiological tissue mobilization and a decrease in body condition are observed. However, in case of an extreme negative energy balance, excessive tissue mobilization occurs and the metabolizing capacity of the liver is exceeded, leading to metabolic disorders such as ketosis and fatty liver syndrome (Duffield, 2000; Bobe et al., 2004).

Monensin is an ionophore antibiotic that is used in ketosis prevention and as a production enhancer in dairy cows (Ipharraguerre and Clark, 2003). When added to the diet, it increases ruminal production of propionate through alterations in the rumen microbiota, causing an increased hepatic gluconeogenesis and thereby increasing the energy supply to the animal (Russell and 
Strobel, 1989; Ipharraguerre and Clark, 2003). The use of antibiotics as feed additives has been banned in the European Union, but monensin was recently launched as an intraruminally applied controlled-release capsule (CRC) indicated for overconditioned transition dairy cows (only upon veterinary prescription; Calsamiglia et al., 2007; Drong et al., 2016a). It has been proposed that monensin preferentially inhibits gram-positive bacteria but tracing its activity to specific microbial groups has been a challenge and systematic studies are lacking (Weimer et al., 2008). Furthermore, it has been shown that monensin decreases methane emissions from ruminants (Boadi et al., 2004). Different studies suggest that monensin does not act directly on rumen methanogens but rather acts by limiting substrate availability through the inhibition of other rumen microorganisms. Functional relationships among microbes, however, have not yet been identified (Hook et al., 2009).

Essential oils have gained a lot of attention in the last decade, and several studies have indicated an effect on rumen fermentation similar to that of monensin (Calsamiglia et al., 2007). However, until now, results have not been consistent concerning the effects of essential oils on rumen fermentation and animal performance, most likely because of variation in dosage and chemical structure of the essential oil used, as well as differing ration compositions and animal physiology among studies (Calsamiglia et al., 2007; Patra, 2011). Patra and Yu (2012) showed, in an in vitro study using denaturing gradient gel electrophoresis analysis and quantitative real-time PCR, that rumen bacterial and archaeal diversity is decreased by different essential oils and stated that sequencing studies should be performed to further investigate these alterations in species composition.

In previous publications, we described the influence of monensin and a specific blend of essential oils (BEO) on performance, energy metabolism, and rumen fermentation, as well as on immunological, hematological and biochemical variables in transition dairy cows (Drong et al., 2016a,b). Increased rumen molar propionate proportions, decreased subclinical and clinical ketosis prevalence, and an influence on liver health and immune system were observed in monensin-supplemented cows, whereas the supplementation of a BEO failed to elicit any effect. In the current study, we aimed to characterize the underlying compositional changes in the rumen microbiota to verify several of the hypotheses regarding the effects of monensin and BEO. Therefore, the microbiota of ruminal liquid samples collected at $d$ 56 postpartum (p.p.) were analyzed using single-strand conformation polymorphism (SSCP) analysis and next-generation Illumina MiSeq amplicon sequencing (Illumina Inc., San Diego, CA). The detected differences in bacterial and archaeal community composition are discussed in the light of our current understanding of monensin and BEO effects.

\section{MATERIALS AND METHODS}

Experimental work was conducted at the experimental station of the Institute of Animal Nutrition (Friedrich-Loeffler-Institute) in Brunswick, Germany. The experiment was carried out in accordance with the German Animal Welfare Act approved by the LAVES (Lower Saxony State Office for Consumer Protection and Food Safety, Germany).

\section{Experimental Design, Sample Collection, and Analysis of Performance and Metabolic Variables}

A trial involving 60 pluriparous German Holstein cows was performed from August 2013 to February 2014 to investigate the effect of monensin and essential oils on performance, energy metabolism, and immunological parameters of transition dairy cows. The experimental design, rations, performance, and energy metabolism and rumen fermentation variables were previously published in Drong et al. (2016a). Variables illustrating the effect of these feed additives on immunity were described in Drong et al. (2016b).

Briefly, the cows were allocated at 6 wk antepartum (a.p.) in either a low-BCS $(2.77 \pm 0.14, \mathrm{n}=15$, parity: $1.7 \pm 0.9$, mean $\pm \mathrm{SD} ; \mathbf{L C})$ or high-BCS $(3.95 \pm 0.08$ $\mathrm{n}=45$ ) group (5-point scale according to Edmonson et al., 1989). The cows in the high-BCS group were then further divided into a control group $(\mathbf{H C}, \mathrm{n}=15$, parity: $2.5 \pm 1.4$ ) and 2 treatment groups receiving either monensin (MO, $\mathrm{n}=15$, parity: $2.6 \pm 1.3$ ) or BEO $(\mathbf{E O}, \mathrm{n}=15$, parity: $2.4 \pm 1.6)$. During the dry period, the LC cows received a ration consisting of $80 \%$ roughage (50\% maize silage, $50 \%$ grass silage) and $20 \%$ concentrate based on DM content. After calving, a TMR was fed with an initial concentrate feed proportion of $30 \%$, which was increased stepwise to $50 \%$ of the daily ration within 2 wk (details in Drong et al., 2016a). The high conditioned animals (HC, MO, and EO groups) were oversupplied with energy during the dry period (concentrate feed proportion of 60\%) and subjected to a slower increase in concentrate feed proportion p.p. (from 30 to $50 \%$ in 3 instead of 2 wk) to stimulate p.p. lipolysis and induce a ketogenic metabolic state (Schulz et al., 2014). In the EO group, a BEO (Crina Ruminants, DSM, Basel, Switzerland) containing thymol (25-35\%), guaiacol (10-15\%), eugenol (5-10\%), vanillin (10-20\%), salicylaldehyde (5-10\%), and limonene $(20-35 \%)$ on an organic carrier (as described in the patent, Rossi, 1999) was administered through the 
pelleted concentrate (target: $1 \mathrm{~g} /$ cow per day) from d 21 a.p. onward. Each cow in the MO group received a monensin CRC (Kexxtone, Elanco, Bad Homburg, Germany) at d 21 a.p. that released $335 \mathrm{mg}$ of monensin/d for $95 \mathrm{~d}$.

The cows were milked 2 times per day at 0530 and $1530 \mathrm{~h}$, and the TMR was fed ad libitum and offered fresh daily at approximately $1100 \mathrm{~h}$. Individual TMR intake was continuously recorded using electronic balance troughs (Insentec, B.V., Marknesse, the Netherlands). Body weight was assessed twice daily after milking and BCS was recorded weekly. Morning and evening milk samples were collected on $2 \mathrm{~d}$ per week (Monday evening and Tuesday morning; Thursday evening and Friday morning) and stored at $4^{\circ} \mathrm{C}$ until analysis. Milk samples were analyzed for fat, protein, lactose, and urea concentrations using an infrared milk analyzer (Milkoscan FT 6000, Foss Electric A/S, Hillerød, Denmark).

Blood samples were collected from an external jugular vein in a $10-\mathrm{mL}$ evacuated serum-separating blood tube, centrifuged immediately thereafter (Heraeus Varifuge 3.0R, Heraeus, Osterode, Germany; 2,300 × $g, 15^{\circ} \mathrm{C}, 15 \mathrm{~min}$ ), and stored at $-80^{\circ} \mathrm{C}$ before chemical analysis for glucose, BHB, fatty acids, urea, albumin, total protein, cholesterol, total bilirubin, and triglyceride concentrations, and aspartate transaminase, $\gamma$-glutamyltransferase, and glutamate dehydrogenase activities using an automatic clinical chemistry analyzer (Eurolyser CCA180, Eurolab, Austria; described in detail in Schären et al., 2016a).

To investigate the influence of these 2 feed additives on rumen microbiota and fermentation variables, rumen fluid samples $(\sim 750 \mathrm{~mL})$ were collected from 48 animals $(\mathrm{n}=12)$ at $\mathrm{d} 56$ p.p. using an oral rumen tube and a hand vacuum pump. Immediately after collection, $\mathrm{pH}$ was measured using a glass electrode (pH 525; WTW, Weilheim, Germany) and samples for microbiota analysis were immediately stored at $-20^{\circ} \mathrm{C}$. For protozoal density assessment, $15 \mathrm{~mL}$ of rumen fluid was mixed with $15 \mathrm{~mL}$ of a methyl green-formalin solution and stored at $4^{\circ} \mathrm{C}$. Protozoa were counted using a Fuchs-Rosenthal chamber under an optical microscope and differentiated into entodiniomorphs and holotrichs (Ogimoto and Imai, 1981). Samples for ammonia $\left(\mathrm{NH}_{3}-\mathrm{N}\right)$, VFA, LPS, and protozoa concentration were cooled to $4^{\circ} \mathrm{C}$ until further processing approximately 1 to $2 \mathrm{~h}$ after sample collection. Volatile fatty acids were determined according to Koch et al. (2006) using a gas chromatograph (model 5890 II, Hewlett Packard, Böblingen, Germany), and $\mathrm{NH}_{3}-\mathrm{N}$ was determined using steam distillation according to the Kjeldahl method (DIN38406-E5-2; Anonymous, 1998). To assess LPS concentrations, rumen fluid samples were centrifuged $\left(10,000 \times g, 30 \mathrm{~min}, 4^{\circ} \mathrm{C}\right)$, filtered, heated, and stored at $-20^{\circ} \mathrm{C}$. For analysis, samples were diluted and measured spectrophotometrically using the Limulus amoebocyte lysate (LAL) assay (Kinetic-QCL, Lonza, Walkersville, MD) following the manufacturer's instructions and using a microplate reader with incubation chamber (Infinite M200, Tecan Group Ltd., Männedorf, Switzerland) and then evaluated using the Magellan Data Analysis Software (Tecan Group Ltd.; detailed protocol in Schären et al., 2016b, and Gozho et al., 2005).

The data presented in the current work were exclusively collected in these 48 cows at d $56 \pm 3$ p.p. (for performance data, means of these $7 \mathrm{~d}$ were calculated). Because of technical issues at that time, several rumen liquid samples for fermentation variable analysis were lost during storage and analysis (especially in LC group). We decided, therefore, to only present the results of the $\mathrm{HC}(\mathrm{n}=9), \mathrm{MO}(\mathrm{n}=12)$, and $\mathrm{EO}(\mathrm{n}=$ 10) groups.

\section{DNA Extraction}

First, several centrifugation steps were performed on the rumen liquid samples to concentrate the bacteria and archaea and to remove feed particles and debris, as follows. The samples were thawed at room temperature, and $80 \mathrm{~mL}$ was centrifuged for $5 \mathrm{~min}$ at $600 \times g\left(4^{\circ} \mathrm{C}\right)$ and the supernatant was kept for further processing. Thereafter, the supernatants were centrifuged 4 times for 20 min at $27,000 \times g\left(4^{\circ} \mathrm{C}\right)$; between each centrifugation step, the pellet was resuspended in $40 \mathrm{~mL}$ of $0.9 \%$ $\mathrm{NaCl}$. After the final centrifugation step, the pellet was resuspended in $1,000 \mu \mathrm{L}$ of $0.9 \% \mathrm{NaCl}$, and single droplets were shock frozen in liquid nitrogen and stored at $-80^{\circ} \mathrm{C}$. The extraction of DNA was adapted from Meibaum et al. (2012). First, $240 \mu \mathrm{L}$ of the microbepellet was thawed on ice and centrifuged $(13,000 \times g, 5$ $\min , 4^{\circ} \mathrm{C}$ ), and the supernatant was discarded. Thereafter, the sample was resuspended in $550 \mu \mathrm{L}$ of $1 \times$ Tris(hydroxymethyl)-aminomethane-HCl, EDTA (both $10 \mathrm{~m} M, \mathrm{pH} 8.0)$, and $\mathrm{NaCl}(150 \mathrm{mM})$, and a mechanical lysis of the cells was performed by bead beating method (Ribolyser Cell Disrupter, Hybaid Ltd., Ashford, UK) in 2 sequences of acceleration $(6.0 \mathrm{~m} / \mathrm{s}$ and $4.5 \mathrm{~m} / \mathrm{s}, 40$ $\mathrm{s}$ each). After centrifugation $\left(13,000 \times \mathrm{g}, 15 \mathrm{~min}, 4^{\circ} \mathrm{C}\right)$, the supernatant was incubated with $50 \mu \mathrm{L}$ of lysozyme $(100 \mathrm{mg} / \mathrm{mL})$ and $10 \mu \mathrm{L}$ of RNaseA $(20 \mathrm{mg} / \mathrm{mL})$ for 30 min at $37^{\circ} \mathrm{C}$. This was followed by an incubation step with $15 \mu \mathrm{L}$ of $20 \%$ SDS and $10 \mu \mathrm{L}$ of proteinase $\mathrm{K}(20 \mathrm{mg} / \mathrm{mL})$ for $1 \mathrm{~h}$ at $37^{\circ} \mathrm{C}$. The final incubation step, using $125 \mu \mathrm{L}$ of $4 \mathrm{M} \mathrm{NaCl}$ and $80 \mu \mathrm{L}$ of $10 \%$ cetyltrimethylammoniumbromide, was performed at $65^{\circ} \mathrm{C}$ for $10 \mathrm{~min}$. To purify the mixture from proteins, $780 \mu \mathrm{L}$ of phenol-chloroform-isoamylalcohol was added, 
the mixture was centrifuged $\left(7 \mathrm{~min}, 13,000 \times \mathrm{g}, 4^{\circ} \mathrm{C}\right)$, the supernatants were discarded, $780 \mu \mathrm{L}$ of chloroformisoamylalcohol was added, the mixture was centrifuged again $\left(10 \mathrm{~min}, 13,000 \times \mathrm{g}, 4^{\circ} \mathrm{C}\right)$, and the supernatant was then kept for further processing. To further purify the DNA, 2 washing steps were performed using the peqGold Tissue-Kit (Peqlab, Erlangen, Germany) according to manufacturer's guidelines. The genomic DNA samples were then stored at $4^{\circ} \mathrm{C}$ until further processing.

\section{PCR-SSCP Analysis}

After DNA extraction, 2-step amplification (initial and nested PCR) of either bacterial or archaeal $16 \mathrm{~S}$ rRNA genes and a single-strand digestion step were performed (protocol and primer described in detail in Meibaum et al., 2012). The 48 samples were then divided onto 4 SSCP gels (12 samples per gel, $\mathrm{n}=3$ ) for bacteria and archaea, and gel electrophoresis was carried out at $300 \mathrm{~V}$ for $22.5 \mathrm{~h}$ at $20^{\circ} \mathrm{C}$ (described in detail in Dohrmann et al., 2004). The gels were digitized and analyzed using ScanMaker (i800, Mikrotek, Willich, Germany) and GelComparII (Applied Maths, SintMartens-Latem, Belgium) as described in Meibaum et al. (2012). For graphical illustration, 2-dimensional principal coordinates analysis plots based on dissimilarities were created with the cmdscale() command in the R 3.0.2 software package (R Core Team, 2013), and all comparisons across the 4 gels were summarized in boxplots as a descriptive illustration.

\section{Prokaryotic 16S rRNA Gene Amplification, Illumina MiSeq Sequencing, and Bioinformatics}

For sequencing, genomic DNA samples were sent to Microsynth AG (Balgach, Switzerland). A primer pair with $97.7 \% / 96.9 \%$ (forward primer) and 98.4\%/96.5\% (reverse primer) coverage (one mismatch) for archaea and bacteria, respectively, was chosen for $16 \mathrm{~S}$ sequencing library preparation: A519F (S-D-Arch-0519-a-S-15): CAGCMGCCGCGGTAA and 802R (S-D-Bact-0785-bA-18): TACNVGGGTATCTAATCC (Klindworth et al., 2013). For 16S rRNA gene amplification, the HiFi HotStart PCR Kit (Kapa Biosystems, Wilmington, MA) was used with following PCR conditions: initial denaturation $\left(95^{\circ} \mathrm{C}, 180 \mathrm{~s}\right)$, denaturation $\left(98^{\circ} \mathrm{C}, 20 \mathrm{~s}\right)$, annealing $\left(50.8^{\circ} \mathrm{C}, 30 \mathrm{~s}\right)$, and elongation $\left(72^{\circ} \mathrm{C}, 30 \mathrm{~s}\right)$ for 30 cycles, and a final elongation step $\left(72^{\circ} \mathrm{C}, 5 \mathrm{~min}\right)$. Furthermore, the Illumina Nextera Libraries were prepared according to the manufacturer's instructions (Illumina Inc., San Diego, CA). Sequencing was performed on the Illumina MiSeq Sequencing System using the Illumina MiSeq reagent Kit v2 $(2 \times 250 \mathrm{bp})$. Sequence data were de-multiplexed and trimmed using the Illumina MiSeq v2.5.1.3. reporter and cutadapt v1.8.1 software package (Martin, 2011). Read stitching was performed using FLASH v1.2.11 (Magoč and Salzberg, 2011), and only stitched reads with an average quality score (whole read) of 25 or higher were used for downstream analysis. Furthermore, de novo chimera detection, identification, and removal was done using the Uchime v4.2 (Edgar et al., 2011) and Usearch v8.1.1861 (Edgar, 2010) software packages. The operational taxonomic units (OTU) clustering (based on 97\% sequence similarity) and the taxonomic assignment was performed using Uclust (Edgar, 2010) and QIIME v1.9.1 (Caporaso et al., 2010), respectively. Singeltons were removed from the data set to reduce bias introduced by sequencing errors. For downstream analysis, only OTU with a relative abundance of at least $0.1 \%$ were considered. As a reference database for the taxonomic assignment, the SILVA rRNA database v111 was chosen (Quast et al., 2013). Alpha diversity analysis was performed and principal components analysis plots were created using QIIME. Robustness of clusters displayed in principal components analysis plots was ensured by jackknife resampling (10-fold).

\section{Statistical Analysis}

All statistical analyses were performed using the $\mathrm{R}$ 3.0.2 software package ( $\mathrm{R}$ Core Team, 2013). If variables were recorded more than once a week, means were calculated per cow and week (d $56 \pm 3$ p.p.) before statistical evaluation. To obtain a normal distribution, rumen LPS concentrations were logarithmically transformed before statistical analysis. For normally distributed data, a one-way ANOVA with Tukey post hoc test was performed, and for non-normal data, a Nemenyi-Damico-Wolfe-Dunn test (joint ranking; Hollander and Wolfe, 1999) modified to function from the $\mathrm{R}$ software package coin (Hothorn et al., 2006) was performed. In case of the SSCP gels, a permutational multivariate analysis of variance (PERMANOVA) was performed using the adonis() function in the R software package vegan (Oksanen et al., 2015). Beta diversity of sequencing results was tested using the anosim() function within the $\mathrm{R}$ package vegan on weighed UniFrac distances. Results were considered significant at $P<$ 0.05 and trends were declared at $0.05<P<0.10$.

\section{RESULTS}

\section{Animal Performance}

No significant differences between groups for DMI, milk production variables (milk yield, milk protein and 
Table 1. Effect of monensin and a blend of essential oils on performance and efficiency in transition dairy cows at d 56 postpartum (p.p.) ${ }^{1}$

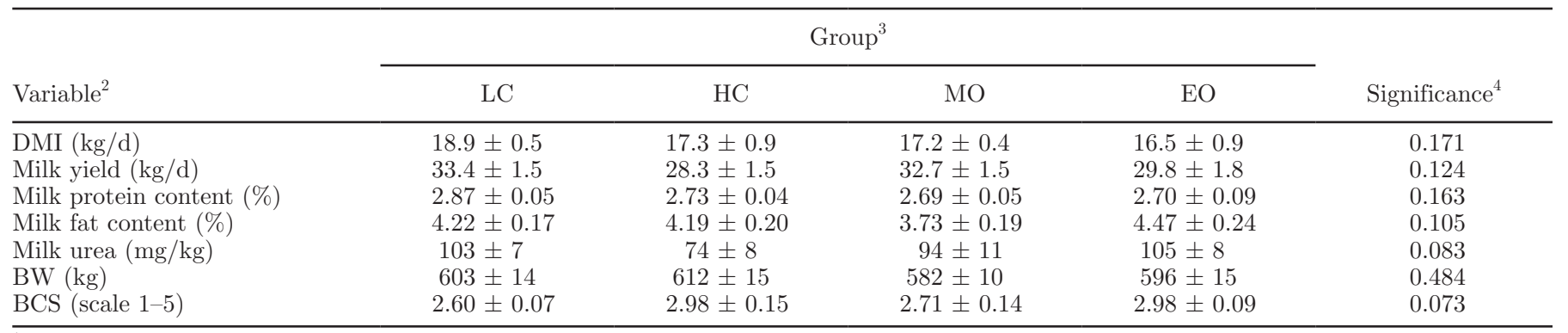

${ }^{1}$ Average of d $56 \pm 3$ p.p.

${ }^{2}$ Means \pm SE.

${ }^{3}$ Animals were divided into a low condition (LC) and a high condition control (HC), monensin (MO), and essential oil (EO) groups 6 wk antepartum (a.p., $\mathrm{n}=12$ ). High-conditioned animals (HC, MO, EO) were oversupplied with energy in the dry period (60 vs. $20 \%$ concentrate feed proportion) and subjected to a decelerated increase in concentrate feed proportion p.p. (from 30 to $50 \%$ in 3 instead of 2 wk) to increase p.p. lipolysis and induce a ketogenic metabolic state. The MO group received a monensin controlled release capsule $21 \mathrm{~d}$ a.p. and the EO group was fed with concentrate containing a blend of essential oils from 3 wk a.p. on and during lactation.

${ }^{4}$ One-way ANOVA, Tukey post hoc test.

fat content and milk urea concentration), or BW and BCS were observed (Table 1).

\section{Rumen Fermentation}

Compared with EO, monensin increased the molar proportion of propionate and decreased the mo- lar proportion of acetate, resulting in a decreased acetate:propionate ratio compared with the $\mathrm{HC}$ and EO groups (Table 2). The monensin treatment also increased the LPS concentration (EO vs. MO: $P=$ 0.108 ) and the concentration of the holotrich protozoa compared with the HC group. No significant differences among groups were observed for $\mathrm{pH}$, total VFA and

Table 2. Effect of monensin and a blend of essential oils on rumen fermentation variables in transition dairy cows at d 56 postpartum (p.p.) ${ }^{1}$

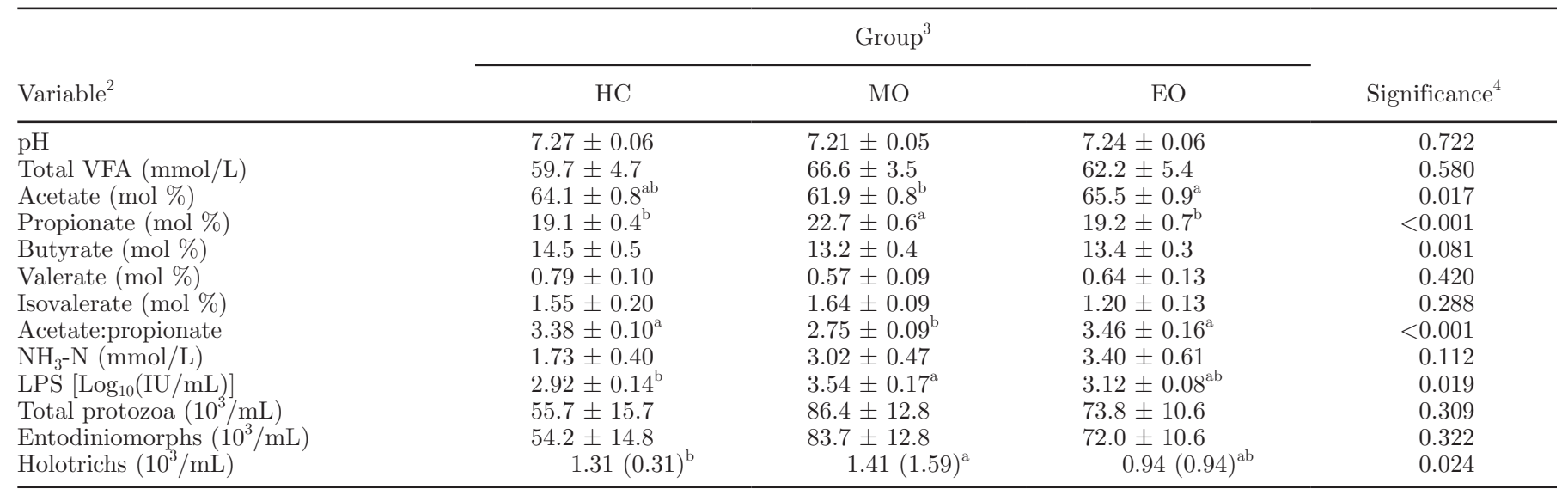

${ }^{\mathrm{a}, \mathrm{b}}$ Values within ration group in a row with different superscript letters differ $(P<0.05)$.

${ }^{1}$ Oral rumen fluid samples were collected at d $56 \pm 1.4$ p.p. (mean $\left.\pm \mathrm{SD}\right)$.

${ }^{2}$ Mean \pm SE for normal distributed data; median (interquartile range) for non-normally distributed data (Holotrichs data only).

${ }^{3}$ Animals were divided into a low condition (LC) and a high condition control (HC), monensin (MO) and essential oil (EO) groups 6 wk antepartum (a.p., $\mathrm{n}=12$ ). High-conditioned animals $(\mathrm{HC}, \mathrm{MO}, \mathrm{EO})$ were oversupplied with energy in the dry period (60 vs. $20 \%$ concentrate feed proportion) and subjected to a decelerated increase in concentrate feed proportion p.p. (from 30 to $50 \%$ in 3 instead of 2 wk) to increase p.p. lipolysis and induce a ketogenic metabolic state. The MO group received a monensin controlled release capsule $21 \mathrm{~d}$ a.p. and the EO group was fed with concentrate containing a blend of essential oils from 3 wk a.p. on and during lactation. Due to technical issues at the time, several samples (especially in the LC group) were lost during storage and analysis. We therefore decided to only present the results of the HC ( $\mathrm{n}=9$ ), MO $(\mathrm{n}=12)$, and EO $(\mathrm{n}=10)$ groups.

${ }^{4}$ A one-way ANOVA with Tukey post hoc test was performed for normally distributed data and a Nemenyi-Damico-Wolfe-Dunn test (Hollander and Wolfe, 1999) was performed for non-normally distributed data (Holotrichs data only). 
Table 3. Effect of monensin and a blend of essential oils on serum clinical chemistry and liver variables in transition dairy cows at d 56 postpartum (p.p. $)^{1}$

\begin{tabular}{|c|c|c|c|c|c|}
\hline Variable $^{2}$ & \multicolumn{4}{|c|}{ Group $^{3}$} & Significance \\
\hline Glucose (mg/dL) & $61.6 \pm 2.3$ & $62.0 \pm 2.4$ & $61.9 \pm 2.5$ & $58.0 \pm 2.4$ & 0.626 \\
\hline Fatty acids (mmol/L) & $0.48 \pm 0.10$ & $0.47 \pm 0.07$ & $0.41 \pm 0.04$ & $0.50 \pm 0.07$ & 0.870 \\
\hline Triglycerides $(\mathrm{mg} / \mathrm{dL})$ & $10.6 \pm 0.5$ & $11.8 \pm 0.7$ & $10.8 \pm 0.4$ & $11.0 \pm 0.9$ & 0.650 \\
\hline Cholesterol (mg/dL) & $204 \pm 9$ & $185 \pm 11$ & $193 \pm 12$ & $186 \pm 12$ & 0.636 \\
\hline AST (IU/L) & $65.7 \pm 5.4$ & $85.5 \pm 8.9$ & $61.3 \pm 3.0$ & $72.0 \pm 6.2$ & 0.061 \\
\hline$\gamma-\mathrm{GT}(\mathrm{IU} / \mathrm{L})$ & $31.3(9.9)$ & $34.5(15.5)$ & $31.5(16.9)$ & $34.1(40.1)$ & 0.947 \\
\hline GLDH (IU/L) & $10.3(9.2)$ & $12.3(7.5)$ & $9.3(13.0)$ & $9.8(12.8)$ & 0.822 \\
\hline Bilirubin (mg/dL) & $0.17 \pm 0.02$ & $0.16 \pm 0.03$ & $0.15 \pm 0.03$ & $0.19 \pm 0.04$ & 0.799 \\
\hline Urea $(\mathrm{mg} / \mathrm{dL})$ & $16.3 \pm 0.8$ & $13.9 \pm 1.3$ & $19.9 \pm 1.9$ & $16.5 \pm 0.9$ & 0.083 \\
\hline
\end{tabular}

\footnotetext{
a,b Values within ration group in a row with different superscript letters differ $(P<0.05)$.

${ }^{1}$ Blood samples were collected at d $56 \pm 1.4$ p.p. (mean $\pm \mathrm{SD}$ ).

${ }^{2} \mathrm{AST}=$ aspartate transaminase, $\gamma$-GT $=\gamma$-glutamyltransferase; GLDH $=$ glutamate dehydrogenase. For normally distributed data, the mean \pm $\mathrm{SE}$ are shown, and for non-normally distributed data ( $\gamma$-GT and GLDH data only), the median (interquartile range) are shown.

${ }^{3}$ Animals were divided into a low condition (LC) and a high condition control (HC), monensin (MO) and essential oil (EO) groups 6 wk antepartum (a.p., $\mathrm{n}=12$ ). High-conditioned animals (HC, MO, EO) were oversupplied with energy in the dry period (60 vs. $20 \%$ concentrate feed proportion) and subjected to a decelerated increase in concentrate feed proportion p.p. (from 30 to $50 \%$ in 3 instead of 2 wk) to increase p.p. lipolysis and induce a ketogenic metabolic state. The MO group received a monensin controlled release capsule $21 \mathrm{~d}$ a.p. and the EO group was fed with concentrate containing a blend of essential oils from 3 wk a.p. on and during lactation.

${ }^{4}$ A one-way ANOVA with Tukey post hoc test was performed for normally distributed data and a Nemenyi-Damico-Wolfe-Dunn test (Hollander and Wolfe, 1999) was performed for non-normally distributed data ( $\gamma$ GT and GLDH data only).
}

$\mathrm{NH}_{3}-\mathrm{N}$ concentrations, butyrate, valerate, and isovalerate proportions, and entodiniomorph and total protozoa counts.

\section{Metabolic Variables}

Higher serum BHB and protein concentrations were measured in the HC group compared with the MO group (Table 3). None of the other serum variables (glucose, fatty acids, triglycerides, cholesterol, albumin, aspartate transaminase, $\gamma$-glutamyltransferase, glutamate dehydrogenase, bilirubin, and urea) differed significantly among groups.

\section{SSCP Analysis}

For the archaea, no clustering was observed for any of the groups on principal coordinates analysis plots, and the PERMANOVA revealed no significant differences among groups for any of the gels (Figure 1). In the boxplots, summarizing the different comparisons across all 4 gels, no differences between comparisons were visible (Figure 2A).

For the bacteria, PERMANOVA revealed a significant difference between groups for 2 of the 4 SSCP gels (Figure $3 \mathrm{~A}$ and $\mathrm{B}$ ). Obvious clustering of the $\mathrm{MO}$ samples was observed on the first gel (Figure 3A) and 2 of the MO samples differed from the other samples on the second gel (Figure 3B). On each of these 2 gels, 2 samples of the EO group were separated from the main cluster with the control animals. For the other 2 gels, no clustering and no significant differences among groups were observed (Figure $3 \mathrm{C}$ and $\mathrm{D}$ ). In the boxplots, summarizing the different comparisons across all 4 gels, a lower dissimilarity among MO samples compared with other groups and comparisons was visible (Figure 2B).

\section{S rRNA Gene Amplicon Analysis}

Illumina MiSeq sequencing resulted in 12,206 $\pm 3,424$ (mean $\pm \mathrm{SD}$ ) reads after filtering per sample. In total, 177 different species-level OTU were identified, with an average of $167 \pm 6$ (mean $\pm \mathrm{SD}$ ) different OTU per sample. Most OTU could be taxonomically classified to the family level, whereas their genus- or species-level affiliation was "uncultured bacterium or archaeon" in many cases.

Alpha diversity analysis revealed decreased species diversity in the MO group, expressed as a lower number of observed OTU in the MO group (compared with all other groups, $\sim 162$ vs. 170 OTU) and a lower Shannon index (compared with HC and LC group, comparison MO vs. EO: $P=0.224$, Table 4 ).

Beta diversity analysis showed a significant difference between groups $(P<0.001)$, and principal components 
A

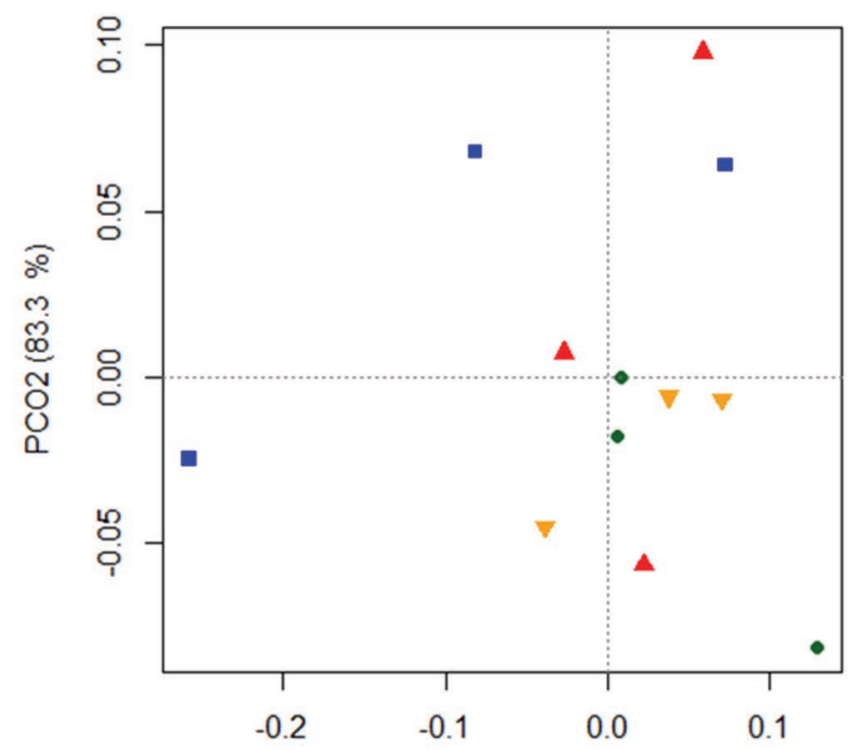

C

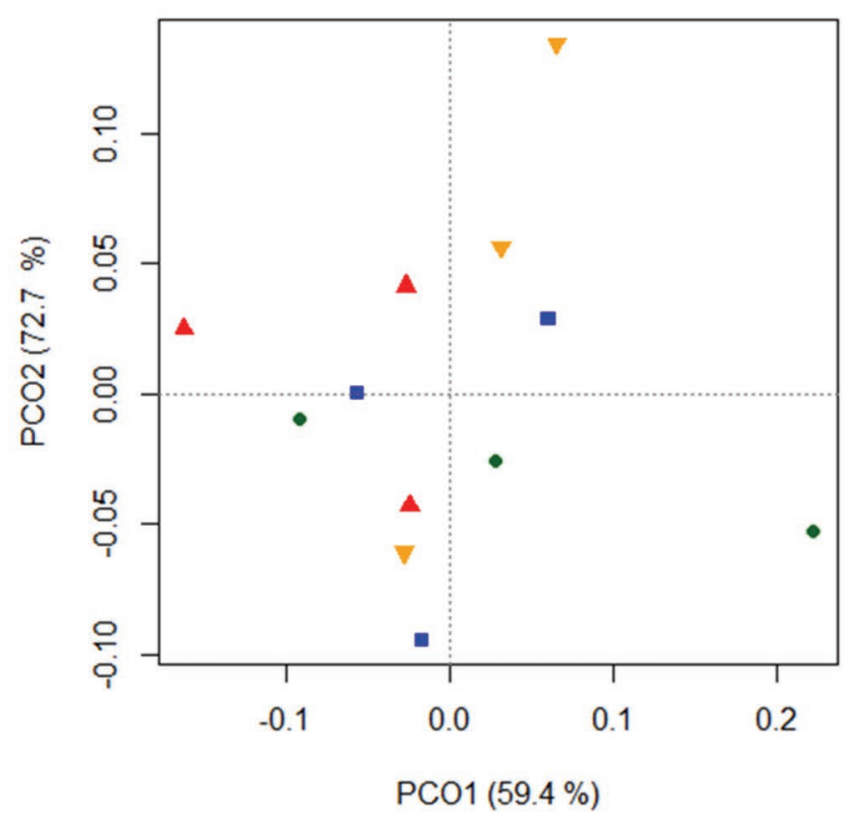

B
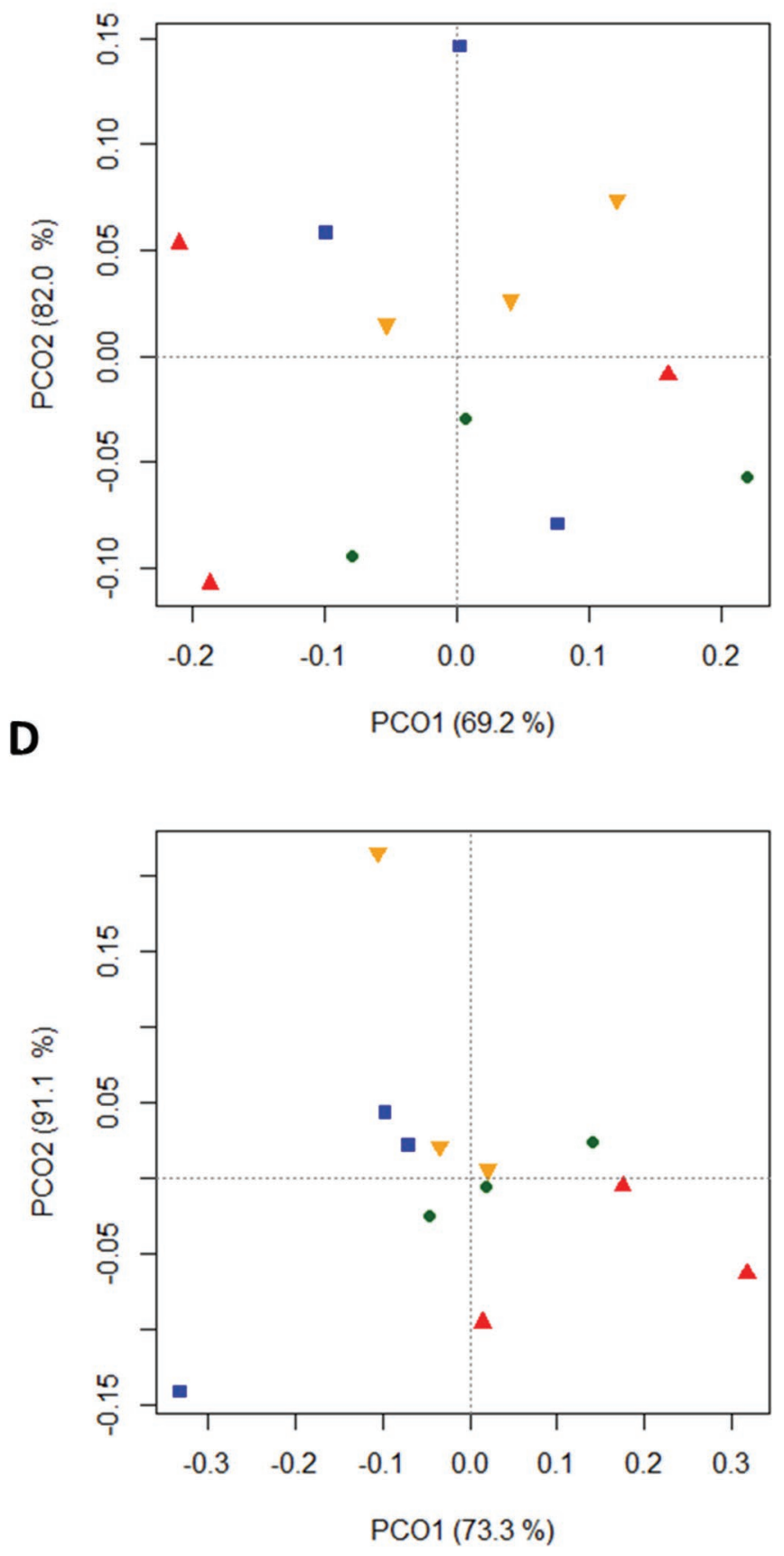

Figure 1. Two-dimensional principal coordinates analysis plots from single-strand conformation polymorphism (SSCP) gels of rumen liquidassociated archaea (explained variance indicated in \% on x- and y-axis). Animals were divided into a low condition (LC, $\mathbf{\square} / \mathrm{blue)}$ and a high condition control (HC, $\mathbf{\nabla}$ /orange), monensin (MO, - green) and essential oil (EO, $\mathbf{\Delta} /$ red) group 6 wk antepartum (a.p., $\mathrm{n}=12$ ). High conditioned animals (HC, MO, EO) were oversupplied with energy in the dry period (60 vs. $20 \%$ concentrate feed proportion) and subjected to a decelerated increase in concentrate feed proportion postpartum (p.p., from 30 to $50 \%$ in 3 instead of 2 wk) to increase p.p. lipolysis and induce a ketogenic metabolic state. The MO group received a monensin controlled release capsule $21 \mathrm{~d}$ a.p. and the EO group was fed with concentrate containing a blend of essential oils from 3 wk a.p. on and during lactation. Rumen liquid samples were collected at d $56 \pm 1.4$ p.p. (mean \pm SD) from 48 animals $(\mathrm{n}=12)$. The samples were divided onto 4 SSCP gels $(\mathrm{A}$ to $\mathrm{D}, 12$ samples per gel, $\mathrm{n}=3)$. Significance: A: $P=0.087, \mathrm{~B}: P=$ $0.561, \mathrm{C}: P=0.753, \mathrm{D}: P=0.175$. Color version available online. 
analysis plots exhibited a clustering of the MO samples (Figure 4). Analysis of the taxonomic composition on family level revealed a decrease in abundance of members of the uncultured BS11 gut group (phylum Bacteroidetes), Rikenellaceae, Lachnospiraceae, and unas- signed OTU, and an increase in abundance of members of the Coriobacteriaceae, Prevotellaceae, S24-7 (phylum Bacteroidetes) and SHA-109 (phylum Cyanobacteria) families in the MO group (Table 5). Within the family Lachnospiraceae, monensin caused a decrease of the

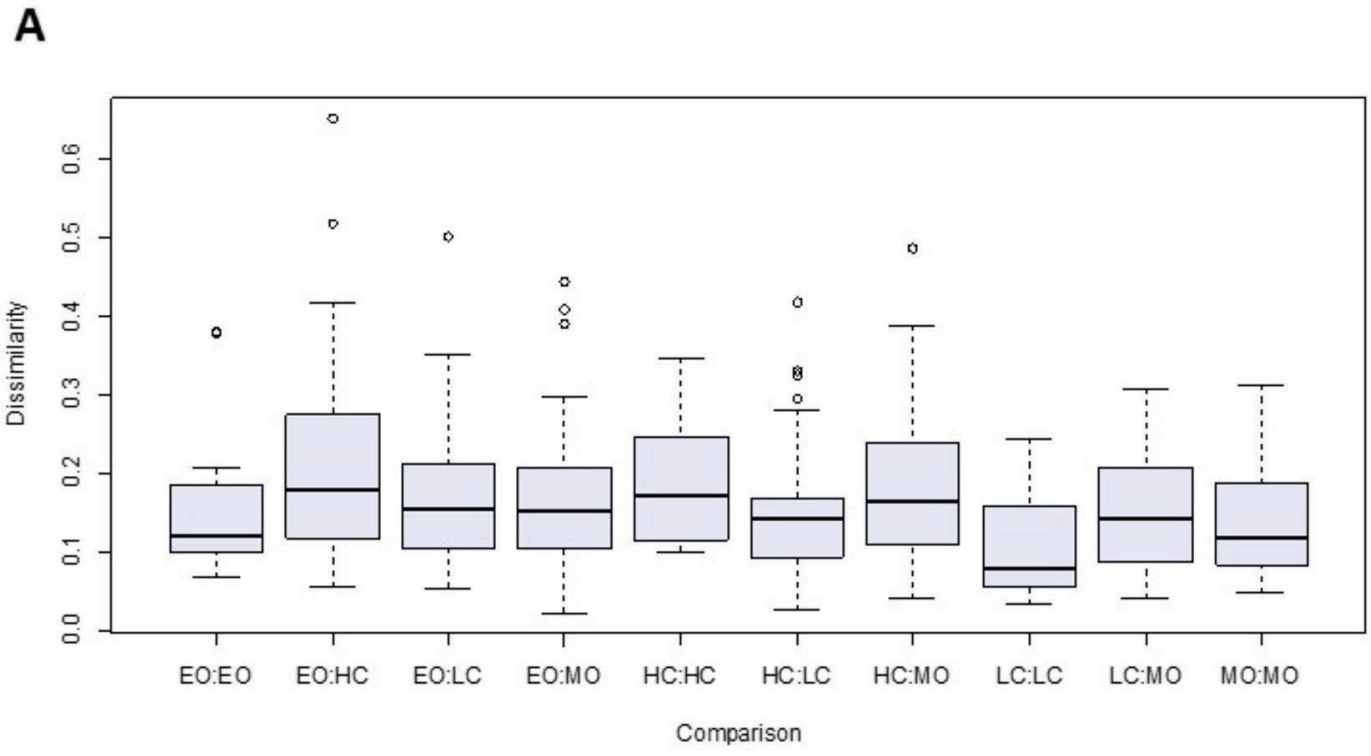

B

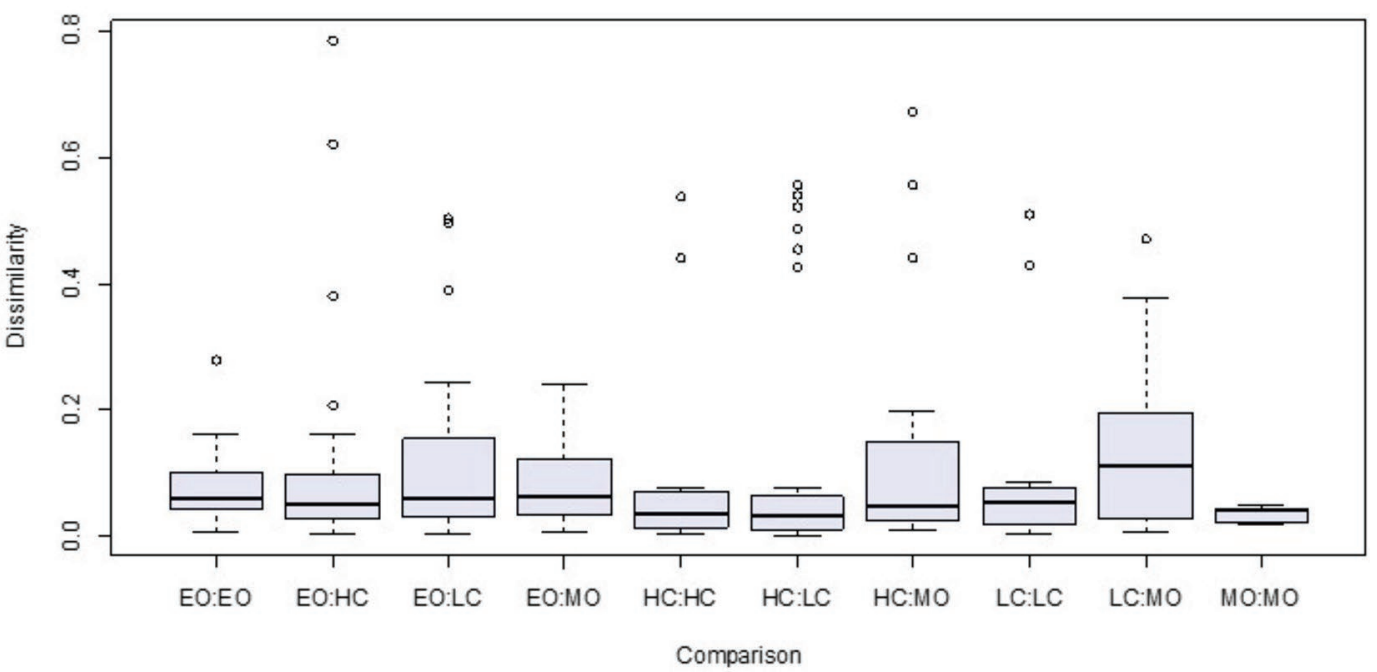

Figure 2. Boxplots summarizing the different comparisons across all 4 single-strand conformation polymorphism (SSCP) gels of rumen liquid associated archaea (A) and bacteria (B). Animals were divided into a low condition (LC) and a high condition control (HC), monensin (MO) and essential oil (EO) groups 6 wk antepartum (a.p., $\mathrm{n}=12$ ). High conditioned animals (HC, MO, EO) were oversupplied with energy in the dry period (60 vs. $20 \%$ concentrate feed proportion) and subjected to a decelerated increase in concentrate feed proportion postpartum (p.p., from 30 to $50 \%$ in 3 instead of $2 \mathrm{wk}$ ) to increase p.p. lipolysis and induce a ketogenic metabolic state. The MO group received a monensin controlled release capsule $21 \mathrm{~d}$ a.p. and the EO group was fed with concentrate containing a blend of essential oils from 3 wk a.p. on and during lactation. Rumen liquid samples were collected at d $56 \pm 1.4$ p.p. (mean \pm SD) from 48 animals $(\mathrm{n}=12)$. The samples were then divided onto 4 SSCP gels (12 samples per gel, $\mathrm{n}=3$ ) for archaea and bacteria, respectively. The rectangle (box) represents the second and third quartiles or the inter-quartile range (IQR); the vertical line inside indicates the median value. The horizontal lines at either side of the rectangle represent the lower (25th percentile) and upper (75th percentile) quartiles. The whiskers indicate the minimum and maximum values or $1.5 \times$ IQR if outliers (defined by $>1.5 \times \mathrm{IQR}$, indicated in circles) are present. Short: box $=$ inter-quartile range with median; whiskers $=$ minimum and maximum; circles $=$ outliers $(>1.5 \times \mathrm{IQR})$. Color version available online. 
A

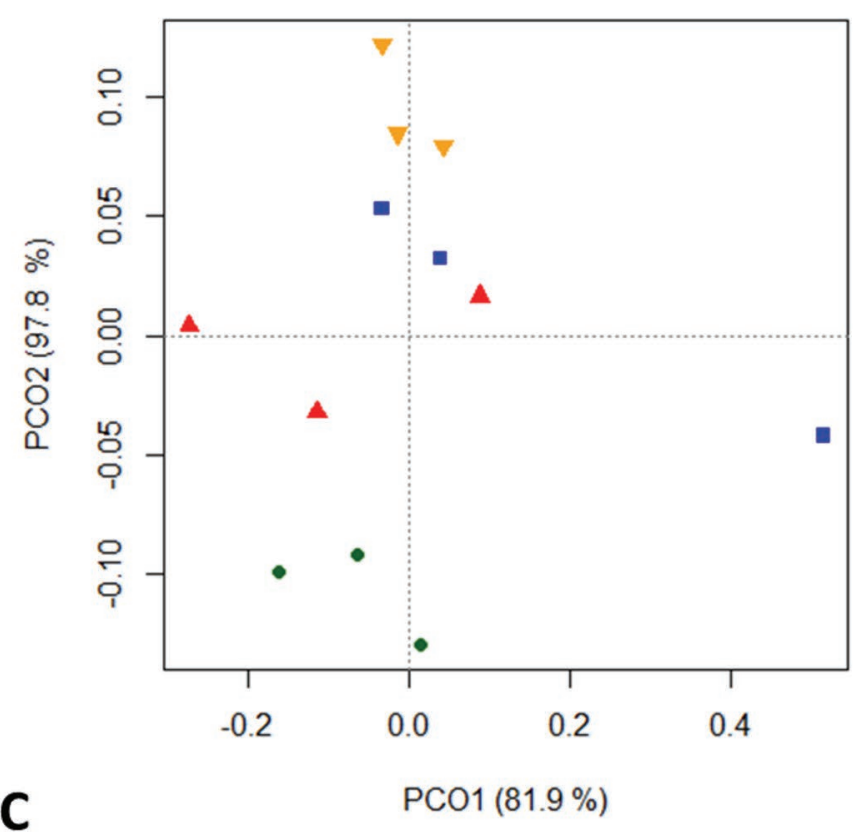

C

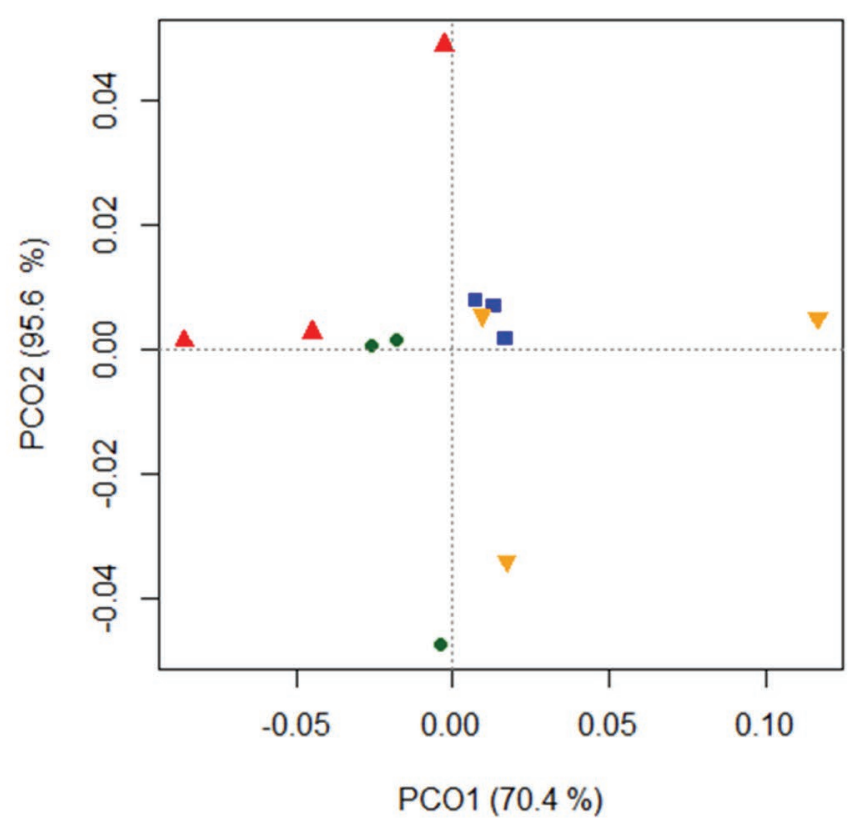

B
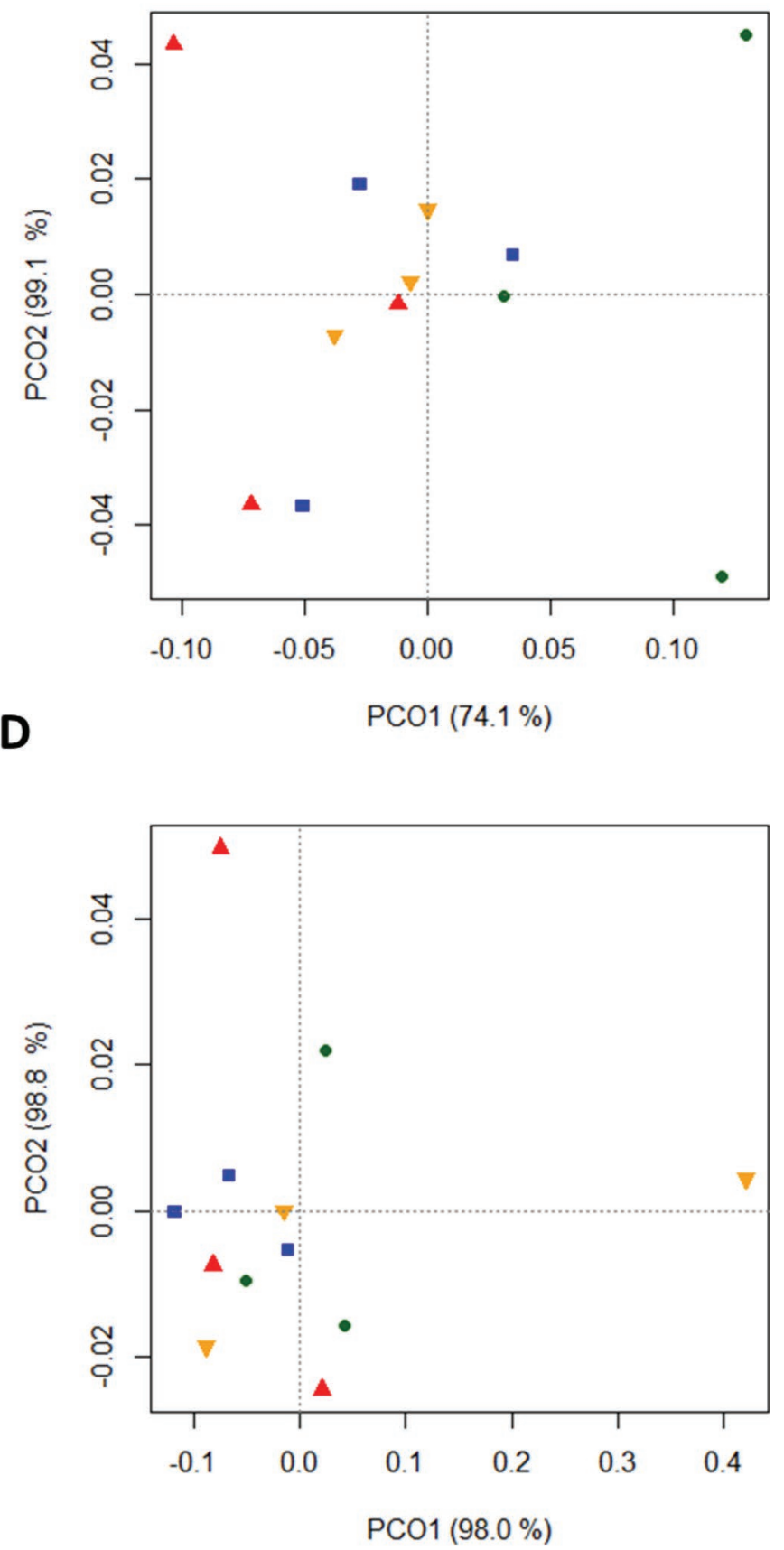

Figure 3. Two-dimensional principal coordinates analysis plots from single-strand conformation polymorphism (SSCP) gels of rumen liquid associated bacteria (explained variance indicated in $\%$ on $\mathrm{x}$ - and $\mathrm{y}$-axis). Animals were divided into a low condition (LC, $\mathbf{0} / \mathrm{blue)}$ and a high condition control (HC, $\mathbf{\nabla}$ /orange), monensin (MO, $\bullet /$ green) and essential oil (EO, $\mathbf{\Delta} /$ red) group 6 wk antepartum (a.p., n = 12). High conditioned animals ( $\mathrm{HC}, \mathrm{MO}, \mathrm{EO}$ ) were oversupplied with energy in the dry period ( $60 \mathrm{vs} .20 \%$ concentrate feed proportion) and subjected to a decelerated increase in concentrate feed proportion postpartum (p.p., from 30 to $50 \%$ in 3 instead of 2 wk) to increase p.p. lipolysis and induce a ketogenic metabolic state. The MO group received a monensin controlled release capsule $21 \mathrm{~d}$ a.p. and the EO group was fed with concentrate containing a blend of essential oils from 3 wk a.p. on and during lactation. Rumen liquid samples were collected at d $56 \pm 1.4$ p.p. (mean \pm SD) from 48 animals $(\mathrm{n}=12)$. The samples were then divided onto 4 SSCP gels (A to $\mathrm{D}, 12$ samples per gel, $\mathrm{n}=3$ ). Significance: A: $P=0.042$, B: $P=0.029, \mathrm{C}: P=0.082, \mathrm{D}: P=0.091$. Color version available online. 
genus Butyrivibrio $(P<0.001)$, Pseudobutyrivibrio $(P$ $=0.068)$, and Incertae sedis $(P=0.005)$, whereas the genus Oribacterium $(P<0.001)$ was increased (data not shown). Of the archaeal population, the only OTU detected was classified as a member of the Methanobrevibacter genus, and its abundance was not influenced by the MO treatment. No difference was observed between the EO and control groups (HC and LC) in archaeal or bacterial abundance at any taxonomic level.

In the MO group, 23 bacterial OTU were identified in which the MO treatment caused a decrease in relative abundance. Those mainly belonged to the phyla Bacteroidetes and Firmicutes (Table 6). Members of the families Rikenellaceae (uncultivated RC9 gut group) and Lachnospiraceae (genera Butyrivibrio and Pseudobutyrivibrio) accounted for $74 \%$ of the decrease in relative abundance, with differences of 3.5 and $4.0 \%$ from the means of the LC, $\mathrm{HC}$, and $\mathrm{EO}$ group (total of $10.1 \%$ ), respectively. For 10 bacterial OTU from the phyla Actinobacteria, Bacteroidetes, Cyanobacteria, and Firmicutes, the monensin treatment resulted in an increase in abundance (total difference of $5.2 \%$ compared with the mean of LC, HC, and EO groups), with the families Lachnospiraceae and Ruminococcaceae being the most important contributors, accounting for 24 and $48 \%$ of the total difference, respectively. When taking into account cell wall constitution and fermentation characteristics (illustrated in Table 7), no clear-cut difference in effect of monensin on gram-negative and gram-positive bacteria was observed.

\section{DISCUSSION}

In a previous paper, we described the production and rumen fermentation characteristics as affected by monensin and a BEO in transition dairy cows. Monensin caused an increase in rumen molar propionate proportions, reducing the occurrence of subclinical or clinical ketosis (Drong et al., 2016a). Furthermore, we observed an influence of monensin on liver health and immune response after vaccination (Drong et al., 2016b). The supplementation of a BEO did not result in alterations in rumen fermentation, production, or immunological factors.

We hypothesized that the observed effects would be mirrored in the rumen microbial community. Therefore, samples of rumen liquid were collected orally at d 56 p.p. for $16 \mathrm{~S}$ rRNA gene analysis. To illustrate the metabolic status of the animals at the time, production data at d $56 \pm 3$ p.p. and clinical chemistry variables assessed at d 56 p.p. were summarized. No difference between groups was observed, which is in line with the observation that monensin mainly elicited an effect during the first 2 wk p.p., when negative energy balance was most pronounced (Drong et al., 2016a). The positive effect of monensin on rumen propionate production, thereby enhancing the energy availability for the animal, was confirmed by the fermentation results (highest propionate proportion and lowest acetate:propionate ratio) and the metabolic variables (lowest serum BHB concentrations in the MO group).

\section{Effect of Essential Oils}

We observed no effect of EO treatment at the rumen microbial level. In vitro and in vivo studies applying similar daily dosages of the same BEO have reached similar results. Benchaar et al. (2003; in vitro, dairy cow rumen fluid), Benchaar et al. (2006; in vivo, dairy cows), Benchaar et al. (2007; in vivo, dairy cows), and Giannenas et al. (2011; in vivo, dairy ewes) reported no influence on ruminal total viable or cellulolytic bacteria counts or protozoa numbers. Only Giannenas et al. (2011) reported a decrease in hyper-ammoniaproducing (HAP) bacteria counts, which is in line with in vitro experiments of McIntosh et al. (2003),

Table 4. Effect of monensin and a blend of essential oils on rumen microbiome diversity (median with interquartile range in parentheses) ${ }^{1}$

\begin{tabular}{|c|c|c|c|c|c|}
\hline \multirow[b]{2}{*}{ Variable } & \multicolumn{4}{|c|}{ Group $^{2}$} & \multirow[b]{2}{*}{ Significance 3} \\
\hline & $\mathrm{LC}$ & $\mathrm{HC}$ & MO & $\mathrm{EO}$ & \\
\hline Chao1 & $172.4(4.3)$ & $171.3(2.2)$ & $166.8(5.7)$ & $171.0(7.5)$ & 0.323 \\
\hline Observed species & $170.5(4.0)^{\mathrm{a}}$ & $171.0(4.5)^{\mathrm{a}}$ & $162.5(4.0)^{\mathrm{b}}$ & $170.5(8.5)^{\mathrm{a}}$ & 0.015 \\
\hline Shannon index & $4.43(0.16)^{\mathrm{a}}$ & $4.41(0.23)^{\mathrm{a}}$ & $4.20(0.13)^{\mathrm{b}}$ & $4.39(0.37)^{\mathrm{ab}}$ & 0.020 \\
\hline
\end{tabular}

\footnotetext{
${ }_{\mathrm{a}, \mathrm{b}}$ Values within ration group in a row with different superscript letters differ $(P<0.05)$.

${ }^{1}$ Oral rumen fluid samples were collected at d $56 \pm 1.4$ postpartum (p.p., mean \pm SD).

${ }^{2}$ Animals were divided into a low condition (LC) and a high condition control (HC), monensin (MO) and essential oil (EO) groups 6 wk antepartum (a.p., $\mathrm{n}=12$ ). High-conditioned animals (HC, MO, EO) were oversupplied with energy in the dry period (60 vs. $20 \%$ concentrate feed proportion) and subjected to a decelerated increase in concentrate feed proportion p.p. (from 30 to $50 \%$ in 3 instead of 2 wk) to increase p.p. lipolysis and induce a ketogenic metabolic state. The MO group received a monensin controlled release capsule $21 \mathrm{~d}$ a.p. and the EO group was fed with concentrate containing a blend of essential oils from 3 wk a.p. on and during lactation.

${ }^{3}$ Nemenyi-Damico-Wolfe-Dunn test (Hollander and Wolfe, 1999).
} 

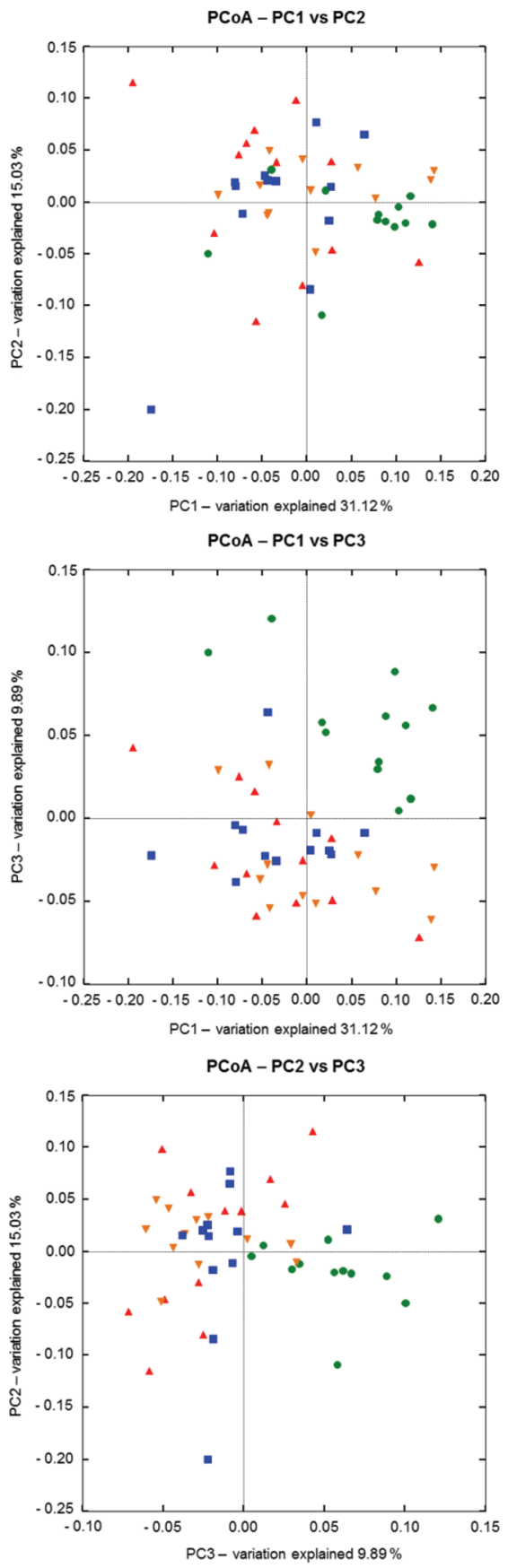

Figure 4. Two-dimensional principal components analysis plots of $16 \mathrm{~S}$ rRNA sequencing results of rumen liquid-associated archaea and bacteria. Animals were divided into a low condition (LC, $\mathbf{\square}$ blue) and a high condition control (HC, $\mathbf{\nabla} /$ orange), monensin (MO, $\bullet$ /green) and essential oil (EO, $\mathbf{\Delta} /$ red) group 6 wk antepartum (a.p., $\mathrm{n}=12$ ). High conditioned animals ( $\mathrm{HC}, \mathrm{MO}, \mathrm{EO})$ were oversupplied with energy in the dry period (60 vs. $20 \%$ concentrate feed proportion) and subjected to a decelerated increase in concentrate feed proportion postpartum (p.p., from 30 to $50 \%$ in 3 instead of $2 \mathrm{wk}$ ) to increase p.p. lipolysis and induce a ketogenic metabolic state. The MO group received a monensin controlled release capsule $21 \mathrm{~d}$ a.p. and the EO group was fed with concentrate containing a blend of essential oils from 3 wk a.p. on and during lactation. Rumen liquid samples were collected at d $56 \pm 1.4$ p.p. (mean $\pm \mathrm{SD})$ from 48 animals $(\mathrm{n}=12)$. Color version available online. which showed that the growth of certain HAP bacteria is inhibited by a BEO. McIntosh et al. (2003) further observed an adaptation to essential oils in several bacterial strains. This was confirmed by Cardozo et al. (2004) in a continuous culture fermentation study that included different essential oils. The aspects of rumen microbiota adaptation and the discrepancy between in vitro and in vivo conditions concerning the effect of essential oils have been discussed by Benchaar and Greathead (2011), who stated that observations in short-term experiments or in vitro experiments, with high concentrations of essential oils that could not be achieved in vivo, may lead to inaccurate conclusions. In the current study, the BEO was fed for approximately $80 \mathrm{~d}$ before sampling. A possible explanation for the absence of effects of BEO supplementation could therefore be the long exposure period and subsequent adaptation of the rumen microbiota.

\section{Comparison of DNA-Based Microbiota Analysis Techniques}

The influence of monensin on the rumen bacteria community could be demonstrated by both methodological approaches to assessing microbial diversity; that is, by sequencing and PCR-SSCP. However, results were much less clear for the latter technique. On only 2 of 4 gels was the monensin effect clearly visible and statistically significant. The descriptive illustration of the different comparisons across all 4 gels revealed much lower dissimilarity among MO samples, which was confirmed by the sequencing results. The difference in results could be attributed to the smaller number of observations on each gel $(\mathrm{n}=3)$ compared with the sequencing analysis $(\mathrm{n}=12)$ due to high inter-animal variation (Weimer, 2015). On the other hand, when comparing the principal components analysis plots of the sequencing results with the principal coordinates analysis plots of the PCR-SSCP analysis, no pattern concerning samples and outliers emerged (data not shown). A second aspect that could explain the discrepancy between results of these 2 methods is the use of different primers for the 16S rRNA gene amplification (Klindworth et al., 2013). However, all primers used in the current trial exhibit high coverage, and the sequencing results showed that alterations due to the MO treatment were substantial enough to be captured with the primers used for the PCR-SSCP analysis. We suggest the limited resolution inherent to this gel-based method and the greater number of available data points for statistical analysis in the amplicon sequencing approach most likely explain the lower sensitivity of the PCR-SSCP method (Kisand and Wikner, 2003; Shendure and Ji, 2008). The output of the PCR-SSCP method consisted only of dissimilari- 
SCHÄREN ET AL.

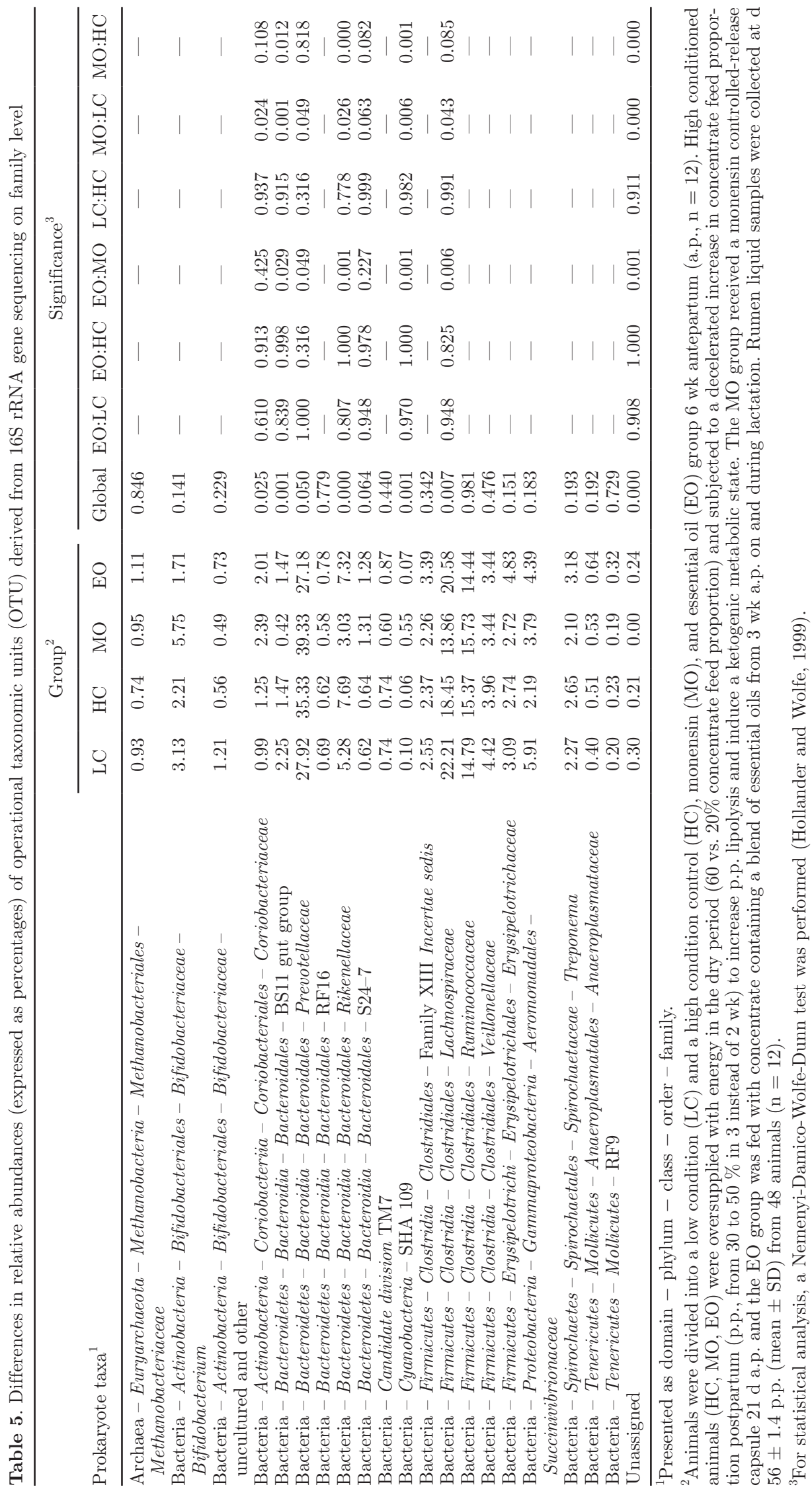




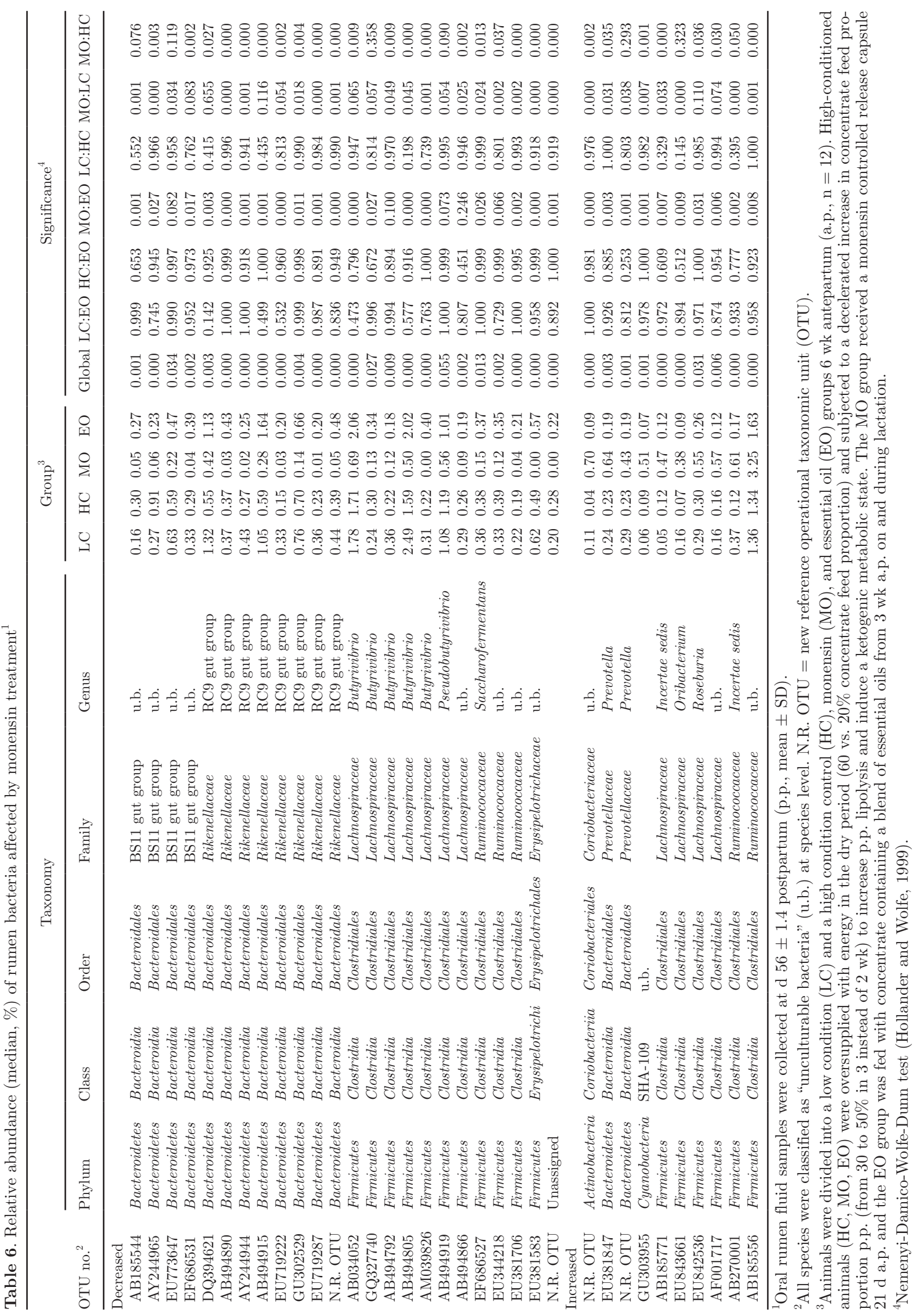




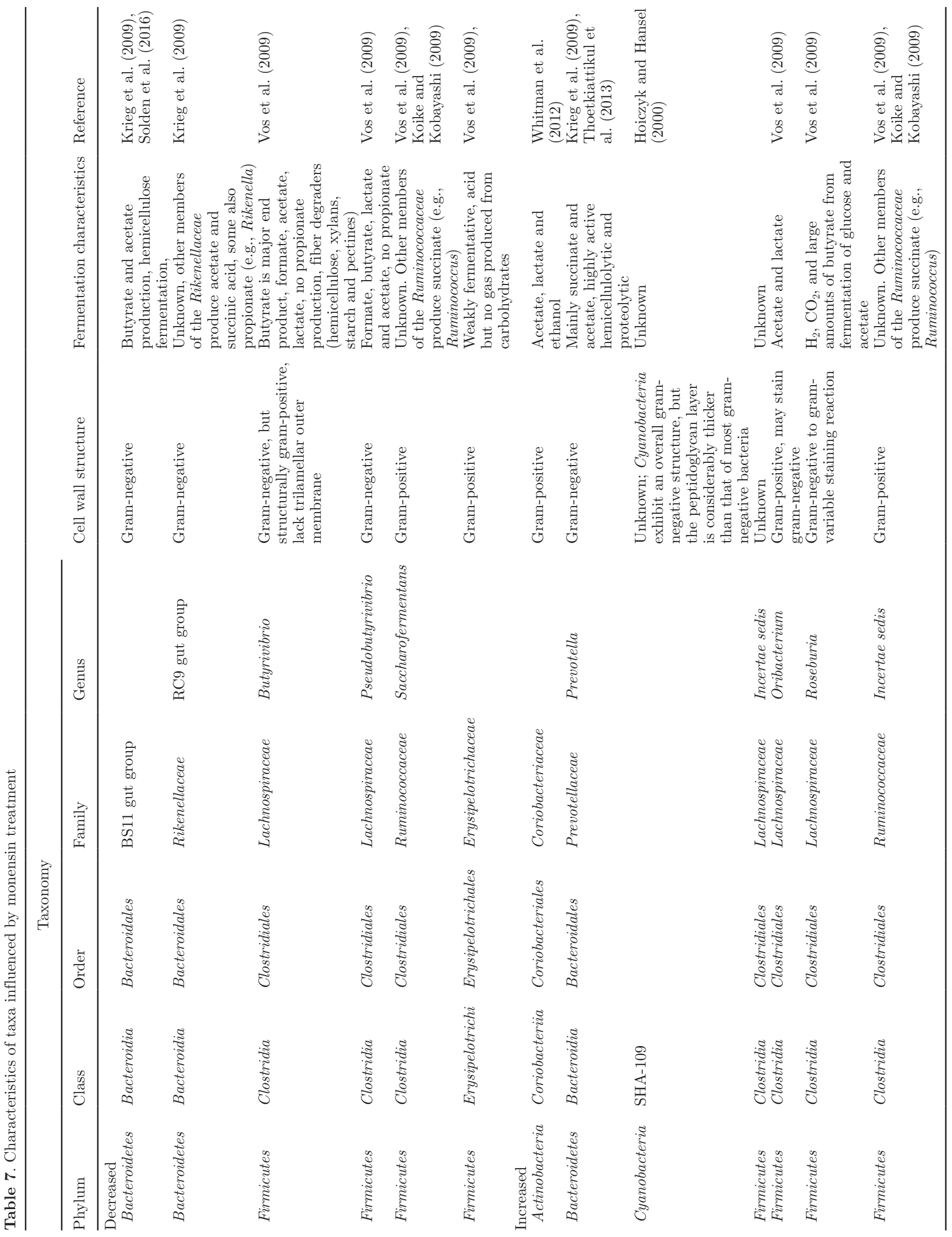


ties between samples, whereas the amplicon sequencing method rendered the proportional abundance of approximately 170 different OTU per sample. These results illustrate that the method used may significantly influence the results of microbiome studies (Weimer, 2015). They further indicate that amplicon sequencing seems to be the more reliable method and constitutes a promising method for routine screening in the future (Shendure and Ji, 2008; Caporaso et al., 2012).

\section{Effect of Monensin on Rumen Microbiota}

Ionophores accumulate in cell membranes and act as antiporters by increasing the influx of sodium and protons, depleting the cell of potassium (Russell and Houlihan, 2003). Therefore, ionophore resistance is mainly correlated with differences in cell envelope structure (Russell and Houlihan, 2003). Different studies have pointed out that rather than a clear-cut difference between gram-negative and gram-positive bacteria, a model of varying effect depending on cell wall constitution and thickness applies (Callaway et al., 1999; Russell and Houlihan, 2003; Weimer et al., 2008), which was also confirmed in our study. We further observed higher LPS concentrations in ruminal fluid in the MO group compared with the HC group. This is in line with the hypothesis that monensin selects for bacterial groups with less-permeable cell walls (Beveridge, 1999; Weimer et al., 2008).

The $16 \mathrm{~S}$ rRNA gene sequencing revealed 23 bacterial OTU belonging to the phyla Bacteroidetes and Firmicutes that exhibited a decrease in relative abundance under the influence of monensin. In contrast, the abundance of 10 bacterial OTU from the phyla Actinobacteria, Bacteroidetes, Cyanobacteria, and Firmicutes was increased. These results illustrate that monensin significantly alters the composition of what has been described as the core microbiome and decreases its diversity (Creevey et al., 2014; Weimer, 2015). Our results are generally in line with the study of Weimer et al. (2008), in which the effect of monensin feeding and withdrawal on populations of individual bacterial species was investigated using real-time PCR in 2 cows receiving a high-starch ration. Similar to our results, they observed an increase in the genus Prevotella, a decrease in a species of the Butyrivibrio genus, and no alterations in the genus Ruminococcus, a species of the genera Ruminobacter and Selenomonas, a species of the family Succinivibrionaceae and the domain Archaea. They further observed a decline in the species Megasphaera elsdenii and no alterations in the species Eubacterium ruminantium and Fibrobacter succinogenes, 3 bacteria species that were not detected in our study. Similar alterations were observed in a study of Kim et al. (2014a,b), investigating the effect of monensin supplementation on ruminal bacterial communities of dairy and feedlot cattle, respectively, using nextgeneration sequencing. However, the results of those studies differ from the current study on various levels. For example, Kim et al. (2014b) observed, similar to our results, an increase in the relative abundance of the family Lachnospiraceae and genus Prevotella, as well as a decrease in the family Ruminococcaceae, but also a decrease in abundance in the genera Oscillobacter, Ruminococcus, Succiniclasticum, Syntrophococcus, and Sharpea, which were either not detected (Oscillobacter and Sharpea) or not altered (Ruminococcus, Succiniclasticum, and Syntrophococcus) in our study. In contrast, we observed alterations in abundance of different bacteria on the phylum (Cyanobacteria), family, and species [BS11 gut group, Rikenellaceae (RC9 gut group), Lachnospiraceae (Pseudobutyrivibrio and Oribacterium)] levels that were not described by Kim et al. (2014b). Kim et al. (2014a) observed alterations in the phyla Firmicutes, Bacteroidetes, Actinobacteria, and Cyanobacteria, similar to our results. Kim et al. (2014a) also observed various alterations in other bacteria taxa that were either not detected (e.g., genus Moryella, family Porphyromonadaceae, and order Streptophyta) or were unaltered in our study (e.g., phylum TM7, genera Succiniclasticum and Syntrophococcus). The differences between the results of those 2 studies and the current study can most likely be attributed to several factors, such as the different rations fed (ground corn and long alfalfa hay in Kim et al., 2014a; $60 \%$ dried distillers grain, corn and corn-silage in Kim et al., 2014b versus a TMR consisting of corn- and grasssilage and concentrate; Henderson et al., 2015), the different DNA extraction methods (Henderson et al., 2013), primers and sequencing system used (targeting of V1-V3 vs. V4-V5 hypervariable region, 454 GS FLX Titanium vs. Illumina MiSeq system; Klindworth et al., $2013)$, and the lower number of reads per sample $(6,268$ and 7,616 vs. 12,206 reads per sample). Furthermore, the samples in the study of Kim et al. (2014a) and Kim et al. (2014b) were collected from 8 and 6 cannulated animals, respectively, and pooled per group for sequencing, whereas in our study, samples from 12 animals in each group were analyzed separately. Also, the length of exposure (21 d and "information missing" vs. $80 \mathrm{~d}$ ) as well as the daily dosage (13 and $33 \mathrm{mg} / \mathrm{kg}$ vs. 19 $\mathrm{mg} / \mathrm{kg}$ of DM; 268 and $274 \mathrm{mg} / \mathrm{d}$ vs. $335 \mathrm{mg} / \mathrm{d}$ ) could play a role in the observed differences. Several studies showed that the sensitivity of different bacteria species and strains to monensin varies with its concentration and that certain bacteria strains are able to increase their resistance over time, most likely by altering their cell wall structure (Russell and Houlihan, 2003; Weimer 
et al., 2011). Furthermore, it is known that the rumen microbiota of the liquid and fiber rumen content differs and monensin may act differently on the 2 fractions because of its feed-particle binding properties (Callaway et al., 1999; Cho et al., 2006; Wischer et al., 2013). In Kim et al. (2014b), it was unclear if the sample was a mixture of both fractions or the samples contained only liquid rumen content. However, Kim et al. (2014a) differentiated between the rumen liquid- and fiber-associated bacteria, and their results (obtained from the analysis of 6 pooled samples) point toward a confirmation of this hypothesis. Kim et al. (2014a) also noted that the form in which monensin is supplied may play a role in the response of the microbial community. Summarizing these different methodological aspects, future studies should involve metagenome sequencing to avoid selection of certain taxa by $16 \mathrm{~S}$ rRNA gene primers, a prolonged trial period with repeated measurements to involve adaptational aspects, different rations and forms in which monensin is supplied, as well as the analysis of the influence on different rumen microbial communities at the different locations in the rumen (the liquid-, fiber-, and epithelium-associated microbiota; Cho et al., 2006).

The effect of monensin on enhancing rumen propionate production was discovered several decades ago, but tracing the underlying mode of action has been a challenge (Weimer et al., 2008). Callaway et al. (1999) stated that Butyrivibrio fibrosolvens is an important acetate and butyrate producer and the ability of monensin to inhibit bacteria of the Butyrivibrio genus might result in increased propionate production. In our trial, most bacterial taxa that were significantly decreased in abundance by monensin are described as moderate producers or non-producers of propionate, which is in line with this hypothesis. Additionally, we observed an increase in abundance of members of 2 taxa that have been described as succinate and propionate producers (Prevotella and Ruminococcaceae; Koike and Kobayashi, 2009; Krieg et al., 2009; Vos et al., 2009; Watanabe et al., 2010). Because succinate is rapidly converted into propionate by succinate-decarboxylating bacteria in the rumen (Koike and Kobayashi, 2009), this might be an additional indication of how monensin alters the rumen fermentation profile.

Unfortunately, most ruminal bacteria species have not been cultured, and the functional properties of and interrelations between different microbial species in vivo are poorly understood. New cultivation-independent techniques, however, promise new insight into rumen microbiota dynamics (Morgavi et al., 2013). For example, Solden et al. (2016) have shown by metagenome sequencing and shotgun proteomics that members of the as-yet-uncultivated Bacteroides BS11 gut group, which was monensin sensitive in our study (Tables 6 and 7 ), is likely a hemicellulose fermenter that produces acetate and butyrate.

Earlier studies suggested that monensin causes a decreased degradation of CP in the rumen through an inhibitory effect on HAP bacteria (Wischer et al., 2013). A decrease in rumen liquid $\mathrm{NH}_{3}-\mathrm{N}$ concentrations and HAP bacteria have been described under the influence of monensin in vitro (Yang and Russell, 1993a; Eschenlauer et al., 2002) as well as in vivo (Yang and Russell, 1993b; Ruiz et al., 2001). In the current study, we did not observe lower $\mathrm{NH}_{3}$ - $\mathrm{N}$ concentrations in the rumen of the monensin-supplemented animals and, to our knowledge, none of the bacteria that were decreased under the influence of monensin have been described as high amino acid fermenters. However, Lana and Russell (1997) found that monensin may increase or decrease rumen $\mathrm{NH}_{3}-\mathrm{N}$ concentrations, depending on the basal diet fed, but that monensin decreases the deamination rate consistently. Therefore, future studies should include this aspect.

Appuhamy et al. (2013) showed in a meta-analysis that addition of monensin to the diet results in a reduction in methane production of 2 and $15 \%$ in dairy cows and beef cattle, respectively (average: $5.4 \%$ ). It has been widely acknowledged that monensin does not act on methanogenic bacteria directly but most likely through suppression of other rumen microorganisms that convert more complex organic matter into substrates for methanogenesis (Hook et al., 2009; Mackie et al., 2013). This was also confirmed in our study, by the PCRSSCP as well as the sequencing approach, where no alteration in the relative abundance of the archaeal taxa was observed. Using the hydrogen provided by other bacteria, methanogens generally produce methane from a variety of carbon substrates such as carbon dioxide, methanol, methylamines, or acetate (Valdez-Vazquez and Poggi-Varaldo, 2009). The amount of hydrogen generated in the rumen is directly influenced by the VFA pattern of fermentation. Hydrogen is produced during glycolysis and the final synthesis of VFA in the rumen. The production of $1 \mathrm{~mol}$ of acetate results in $2 \mathrm{~mol}$ of hydrogen, whereas the production of $1 \mathrm{~mol}$ of propionate renders only $1 \mathrm{~mol}$ of hydrogen (Czerkawski, 1986). The shift of the acetate:propionate ratio caused by monensin therefore leads to a decrease in methane, as demonstrated by Wischer et al. (2013). Other possible and suggested pathways leading to a reduction in methane production, such as an increase in bacteria species that compete for hydrogen (e.g., sulfate reducers and acetogens; Morvan et al., 1996; Valdez-Vazquez and Poggi-Varaldo, 2009; Mackie et al., 2013) or a decrease in hydrogen production through the inhibition of protozoa (Russell and Strobel, 1989), are not supported 
by the data of the current study. We observed no effects on total protozoal counts or entodiniomorph protozoa, and the highest holotrich protozoa concentrations were detected in the MO group in addition to high variation between animals. This is in line with different studies observing a variable and transient effect of monensin on rumen protozoa (Dennis et al., 1986; Arakaki et al., 2000; Benchaar et al., 2006; Sylvester et al., 2009).

\section{CONCLUSIONS}

Intraruminal application of monensin decreased rumen microbiome diversity by acting on the core microbiome, whereas the applied BEO (containing thymol, guaiacol, eugenol, vanillin, salicylaldehyde, and limonene) failed to elicit any effects. We confirmed that, rather than a clear-cut difference between gram-negative and gram-positive bacteria, a model of varying effects depending on cell-wall constitution and thickness applies in monensin sensitivity. These data support the hypothesis that the observed increased proportion of ruminal molar propionate due to monensin may be caused by a decrease in abundance of propionate non-producers and moderate producers and an increase in abundance of succinate producers, such as the Prevotella genus. The decreased production of methane observed under monensin supplementation most likely cannot be ascribed to a direct effect of monensin on the methanogens but rather to a decrease in substrate availability for methanogenesis by acting on other rumen microorganisms. By applying 2 methods (DNA fingerprinting and sequencing) and comparing our results to those of other studies that used different methods to define alterations in the rumen microbiome, we demonstrated that results can vary and confirm the power of amplicon sequencing for screening purposes. To further investigate the mode of action of monensin and to characterize the resulting alterations in the rumen microbiome, techniques to investigate alterations on a functional level such as metagenomics, metatranscriptomics, or metaproteomics should be applied. Furthermore, the aspects of adaptation and difference between fiber-, liquid-, and rumen epithelium-associated bacteria should be considered in future studies.

\section{ACKNOWLEDGMENTS}

The authors thank Inga Ruddat and Martin Beyerbach (Institute for Biometrics, University of Veterinary Medicine, Hanover, Germany) for excellent bioinformatical support. Many thanks go to the coworkers at the Institute of Animal Nutrition and the experimental station of the Institute of Animal Nutrition, FriedrichLoeffler-Institute (FLI, Braunschweig, Germany) for caring for the experimental animals, assisting with experimental measurements, and performing the analyses. The authors also thank Christian Hundsrucker and Pascal Weigold from Microsynth AG, as well as Andres Buser, for their outstanding consultancy.

\section{REFERENCES}

Anonymous. 1998. DIN 38406-E5-2. Deutsche Einheitsverfahren zur Wasser-, Abwasser- und Schlammuntersuchung. 40. Lieferung. Wiley-VCH, Winheim, Germany.

Appuhamy, J. A. D. R. N., A. B. Strathe, S. Jayasundara, C. WagnerRiddle, J. Dijkstra, J. France, and E. Kebreab. 2013. Anti-methanogenic effects of monensin in dairy and beef cattle: A metaanalysis. J. Dairy Sci. 96:5161-5173.

Arakaki, L. C., R. C. Stahringer, J. E. Garrett, and B. A. Dehority. 2000. The effects of feeding monensin and yeast culture, alone or in combination, on the concentration and generic composition of rumen protozoa in steers fed on low-quality pasture supplemented with increasing levels of concentrate. Anim. Feed Sci. Technol. 84:121-127.

Benchaar, C., and H. Greathead. 2011. Essential oils and opportunities to mitigate enteric methane emissions from ruminants. Anim. Feed Sci. Technol. 166-67:338-355.

Benchaar, C., H. V. Petit, R. Berthiaume, D. R. Ouellet, and J. Chiquette. 2003. Effects of essential oil supplements on ruminal fermentation, rumen microbial populations and in sacco degradation of dry matter and nitrogen in the rumen of lactating dairy cows. Can. J. Anim. Sci. 83:637-638.

Benchaar, C., H. V. Petit, R. Berthiaume, D. R. Ouellet, J. Chiquette, and P. Y. Chouinard. 2007. Effects of essential oils on digestion, ruminal fermentation, rumen microbial populations, milk production, and milk composition in dairy cows fed alfalfa silage or corn silage. J. Dairy Sci. 90:886-897.

Benchaar, C., H. V. Petit, R. Berthiaume, T. D. Whyte, and P. Y. Chouinard. 2006. Effects of addition of essential oils and monensin premix on digestion, ruminal fermentation, milk production, and milk composition in dairy cows. J. Dairy Sci. 89:4352-4364.

Beveridge, T. J. 1999. Structures of gram-negative cell walls and their derived membrane vesicles. J. Bacteriol. 181:4725-4733.

Boadi, D., C. Benchaar, J. Chiquette, and D. Massé. 2004. Mitigation strategies to reduce enteric methane emissions from dairy cows: Update review. Can. J. Anim. Sci. 84:319-335.

Bobe, G., J. W. Young, and D. C. Beitz. 2004. Invited review: Pathology, etiology, prevention, and treatment of fatty liver in dairy cows. J. Dairy Sci. 87:3105-3124.

Callaway, T. R., K. A. Adams, and J. B. Russell. 1999. The ability of "low G + C gram-positive" ruminal bacteria to resist monensin and counteract potassium depletion. Curr. Microbiol. 39:226-230.

Calsamiglia, S., M. Busquet, P. W. Cardozo, L. Castillejos, and A. Ferret. 2007. Essential oils as modifiers of rumen microbial fermentation. J. Dairy Sci. 90:2580-2595.

Caporaso, J. G., J. Kuczynski, J. Stombaugh, K. Bittinger, F. D. Bushman, E. K. Costello, N. Fierer, A. G. Pena, J. K. Goodrich, and J. I. Gordon. 2010. QIIME allows analysis of high-throughput community sequencing data. Nat. Methods 7:335-336.

Caporaso, J. G., C. L. Lauber, W. A. Walters, D. Berg-Lyons, J. Huntley, N. Fierer, S. M. Owens, J. Betley, L. Fraser, M. Bauer, N. Gormley, J. A. Gilbert, G. Smith, and R. Knight. 2012. Ultrahigh-throughput microbial community analysis on the Illumina HiSeq and MiSeq platforms. ISME J. 6:1621-1624.

Cardozo, P. W., S. Calsamiglia, A. Ferret, and C. Kamel. 2004. Effects of natural plant extracts on ruminal protein degradation and fermentation profiles in continuous culture. J. Anim. Sci. 82:32303236 .

Cho, S. J., K. M. Cho, E. C. Shin, W. J. Lim, S. Y. Hong, B. R. Choi, J. M. Kang, S. M. Lee, Y. H. Kim, H. Kim, and H. D. Yun. 2006. $16 \mathrm{~S}$ rDNA analysis of bacterial diversity in three fractions of cow rumen. J. Microbiol. Biotechnol. 16:92-101. 
Creevey, C. J., W. J. Kelly, G. Henderson, and S. C. Leahy. 2014. Determining the culturability of the rumen bacterial microbiome. Microb. Biotechnol. 7:467-479.

Czerkawski, J. W. 1986. An Introduction to Rumen Studies. Pergamon Press, Oxford, UK

Dennis, S. M., T. G. Nagaraja, and A. D. Dayton. 1986. Effect of lasalocid, monensin and thiopeptin on rumen protozoa. Res. Vet. Sci. 41:251-256.

Dohrmann, A. B., C. C. Tebbe, G. A. Kowalchuk, F. J. de Bruijn, I. M. Head, A. D. L. Akkermans, and J. D. van Elsas. 2004. Microbial community analysis by PCR-single-strand conformation polymorphism (PCR-SSCP). Pages 809-838 in Molecular Microbial Ecology Manual. Volumes 1 and 2. Springer, Dordrecht, the Netherlands.

Drong, C., U. Meyer, D. von Soosten, J. Frahm, J. Rehage, G. Breves, and S. Dänicke. 2016a. Effect of monensin and essential oils on performance and energy metabolism of transition dairy cows. J. Anim. Physiol. Anim. Nutr. (Berl.) 100:537-551.

Drong, C., U. Meyer, D. von Soosten, J. Frahm, J. Rehage, G. Breves, and S. Dänicke. 2016b. Effects of monensin and essential oils on immunological, hematological and biochemical parameters of cows during the transition period. J. Anim. Physiol. Anim. Nutr. (Berl.) https://doi.org/10.1111/jpn.12494.

Duffield, T. 2000. Subclinical ketosis in lactating dairy cattle. Vet. Clin. North Am. Food Anim. Pract. 16:231-253.

Edgar, R. C. 2010. Search and clustering orders of magnitude faster than BLAST. Bioinformatics 26:2460-2461.

Edgar, R. C., B. J. Haas, J. C. Clemente, C. Quince, and R. Knight. 2011. UCHIME improves sensitivity and speed of chimera detection. Bioinformatics 27:2194-2200.

Edmonson, A. J., I. J. Lean, L. D. Weaver, T. Farver, and G. Webster. 1989. A body condition scoring chart for Holstein dairy cows. J. Dairy Sci. 72:68-78.

Eschenlauer, S. C., N. McKain, N. D. Walker, N. R. McEwan, C. J. Newbold, and R. J. Wallace. 2002. Ammonia production by ruminal microorganisms and enumeration, isolation, and characterization of bacteria capable of growth on peptides and amino acids from the sheep rumen. Appl. Environ. Microbiol. 68:4925-4931.

Giannenas, I., J. Skoufos, C. Giannakopoulos, M. Wiemann, O. Gortzi, S. Lalas, and I. Kyriazakis. 2011. Effects of essential oils on milk production, milk composition, and rumen microbiota in Chios dairy ewes. J. Dairy Sci. 94:5569-5577.

Gozho, G. N., J. C. Plaizier, D. O. Krause, A. D. Kennedy, and K M. Wittenberg. 2005. Subacute ruminal acidosis induces ruminal lipopolysaccharide endotoxin release and triggers an inflammatory response. J. Dairy Sci. 88:1399-1403.

Henderson, G., F. Cox, S. Ganesh, A. Jonker, W. Young, C. Global Rumen Census, and P. H. Janssen. 2015. Rumen microbial community composition varies with diet and host, but a core microbiome is found across a wide geographical range. Sci. Rep. 5:14567.

Henderson, G., F. Cox, S. Kittelmann, V. H. Miri, M. Zethof, S. J. Noel, G. C. Waghorn, and P. H. Janssen. 2013. Effect of DNA extraction methods and sampling techniques on the apparent structure of cow and sheep rumen microbial communities. PLoS One 8:e74787. https://doi.org/10.1371/journal.pone.0074787.

Hoiczyk, E., and A. Hansel. 2000. Cyanobacterial cell walls: News from an unusual prokaryotic envelope. J. Bacteriol. 182:1191-1199.

Hollander, M., and D. Wolfe. 1999. Nonparametric Statistical Methods: Solutions Manual. 2nd ed. Wiley New York, NY.

Hook, S. E., K. S. Northwood, A. D. G. Wright, and B. W. McBride. 2009. Long-term monensin supplementation does not significantly affect quantity or diversity of methanogens in the rumen of lactating dairy cattle. Can. J. Anim. Sci. 89:150.

Hothorn, T., K. Hornik, M. A. Van de Wiel, and A. Zeileis. 2006. A Lego system for conditional inference. Am. Stat. 60:257-263.

Ipharraguerre, I. R., and J. H. Clark. 2003. Usefulness of ionophores for lactating dairy cows: a review. Anim. Feed Sci. Technol. 106:39-57.

Kim, M., M. L. Eastridge, and Z. Yu. 2014a. Investigation of ruminal bacterial diversity in dairy cattle fed supplementary monensin alone and in combination with fat, using pyrosequencing analysis. Can. J. Microbiol. 60:65-71.
Kim, M., T. L. Felix, S. C. Loerch, and Z. Yu. 2014b. Effect of haylage and monensin supplementation on ruminal bacterial communities of feedlot cattle. Curr. Microbiol. 69:169-175.

Kisand, V., and J. Wikner. 2003. Limited resolution of $16 \mathrm{~S}$ rDNA DGGE caused by melting properties and closely related DNA sequences. J. Microbiol. Methods 54:183-191.

Klindworth, A., E. Pruesse, T. Schweer, J. Peplies, C. Quast, M. Horn, and F. O. Glockner. 2013. Evaluation of general $16 \mathrm{~S}$ ribosomal RNA gene PCR primers for classical and next-generation sequencing-based diversity studies. Nucleic Acids Res. 41:e1.

Koch, M., E. Strobel, C. C. Tebbe, J. Heritage, G. Breves, and K. Huber. 2006. Transgenic maize in the presence of ampicillin modifies the metabolic profile and microbial population structure of bovine rumen fluid in vitro. Br. J. Nutr. 96:820-829.

Koike, S., and Y. Kobayashi. 2009. Fibrolytic rumen bacteria: Their ecology and functions. Asian australas. J. Anim. Sci. 22:131-138.

Krieg, N. R., J. T. Stanley, D. R. Brown, B. P. Hedlund, B. J. Paster, N. L. Ward, W. Ludwig, and B. W. Whitman. 2009. Bergey's Manual of Systematic Bacteriology, Volume 4: The Bacteroidetes, Spirochaetes, Tenericutes (Mollicutes), Acidobacteria, Fibrobacteres, Fusobacteria, Dictyoglomi, Gemmatimonadetes, Lentisphaerae, Verrucomicrobia, Chlamydiae, and Planctomycetes. Springer, New York, NY.

Lana, R. P., and J. B. Russell. 1997. Effect of forage quality and monensin on the ruminal fermentation of fistulated cows fed continuously at a constant intake. J. Anim. Sci. 75:224-229.

Mackie, R. I., C. S. McSweeney, and R. I. Aminov. 2013. Rumen. eLS. John Wiley \& Sons Ltd., Chichester, UK.

Magoč, T., and S. L. Salzberg. 2011. FLASH: Fast length adjustment of short reads to improve genome assemblies. Bioinformatics 27:2957-2963.

Martin, M. 2011. Cutadapt removes adapter sequences from highthroughput sequencing reads. EMBnet J. 17:10-12.

McIntosh, F. M., P. Williams, R. Losa, R. J. Wallace, D. A. Beever, and C. J. Newbold. 2003. Effects of essential oils on ruminal microorganisms and their protein metabolism. Appl. Environ. Microbiol. 69:5011-5014.

Meibaum, B., S. Riede, B. Schröder, R. Manderscheid, H. Weigel, and G. Breves. 2012. Elevated $\mathrm{CO}_{2}$ and drought stress effects on the chemical composition of maize plants, their ruminal fermentation and microbial diversity in vitro. Arch. Anim. Nutr. 66:473-489.

Morgavi, D. P., W. J. Kelly, P. H. Janssen, and G. T. Attwood. 2013 Rumen microbial (meta) genomics and its application to ruminant production. Animal 7:184-201.

Morvan, B., F. Bonnemoy, G. Fonty, and P. Gouet. 1996. Quantitative determination of $\mathrm{H}_{2}$-utilizing acetogenic and sulfate-reducing bacteria and methanogenic archaea from digestive tract of different mammals. Curr. Microbiol. 32:129-133.

Ogimoto, K., and S. Imai. 1981. Atlas of Rumen Microbiology. Japan Scientific Societies Press, Tokyo, Japan.

Oksanen, J., F. G. Blanchet, R. Kindt, P. Legendre, P. R. Minchin, R. B. O'Hara, G. L. Simpson, P. M. Solymos, H. H. Stevens, and H. Wagner. 2015. vegan: Community Ecology Package. R package version 2.2-1. http://CRAN.R-project.org/package=vegan.

Patra, A. K. 2011. Effects of essential oils on rumen fermentation, microbial ecology and ruminant production. Asian J. Anim. Vet. Adv. 6:416-428.

Patra, A. K., and Z. T. Yu. 2012. Effects of essential oils on methane production and fermentation by, and abundance and diversity of, rumen microbial populations. Appl. Environ. Microbiol. 78:42714280.

Quast, C., E. Pruesse, P. Yilmaz, J. Gerken, T. Schweer, P. Yarza, J. Peplies, and F. O. Glöckner. 2013. The SILVA ribosomal RNA gene database project: Improved data processing and web-based tools. Nucleic Acids Res. 41:D590-D596.

R Core Team. 2013. R: A language and environment for statistical computing. R Foundation for Statistical Computing, Vienna, Austria.

Rossi, J. 1999. Additives for animal nutrition and technique for their preparation. European patent EP 0646321 B1. 
Ruiz, R., G. L. Albrecht, L. O. Tedeschi, G. Jarvis, J. B. Russell, and D. G. Fox. 2001. Effect of monensin on the performance and nitrogen utilization of lactating dairy cows consuming fresh forage. J. Dairy Sci. 84:1717-1727.

Russell, J. B., and A. J. Houlihan. 2003. Ionophore resistance of ruminal bacteria and its potential impact on human health. FEMS Microbiol. Rev. 27:65-74.

Russell, J. B., and H. J. Strobel. 1989. Effect of ionophores on ruminal fermentation. Appl. Environ. Microbiol. 55:1-6.

Schären, M., S. Jostmeier, S. Ruesink, L. Hüther, J. Frahm, M. Bulang, U. Meyer, J. Rehage, J. Isselstein, G. Breves, and S. Dänicke. 2016a. The effects of a ration change from a total mixed ration to pasture on health and production of dairy cows. J. Dairy Sci. 99:1183-1200. https://doi.org/10.3168/jds.2015-9873.

Schären, M., G. M. Seyfang, H. Steingass, K. Dieho, J. Dijkstra, L. Hüther, J. Frahm, A. Beineke, D. von Soosten, U. Meyer, G. Breves, and S. Dänicke. 2016b. The effects of a ration change from a total mixed ration to pasture on rumen fermentation, volatile fatty acid absorption characteristics, and morphology of dairy cows. J. Dairy Sci. 99:3549-3565.

Schulz, K., J. Frahm, U. Meyer, S. Kersten, D. Reiche, J. Rehage, and S. Dänicke. 2014. Effects of prepartal body condition score and peripartal energy supply of dairy cows on postpartal lipolysis, energy balance and ketogenesis: An animal model to investigate subclinical ketosis. J. Dairy Res. 81:257-266.

Shendure, J., and H. L. Ji. 2008. Next-generation DNA sequencing. Nat. Biotechnol. 26:1135-1145.

Solden, L. M., D. W. Hoyt, W. B. Collins, J. E. Plank, T. J. Beavers, R. A. Daly, R. Wolfe, C. D. Nicora, S. O. Purvine, M. Carstensen, M. A. Lipton, D. E. Spalinger, J. L. Firkins, B. A. Wolfe, and K. C. Wrighton. 2016. New roles in hemicellulosic sugar fermentation for the uncultivated Bacteroidetes family BS11. Proc. Natl. Acad. Sci. USA. https://doi.org/10.1038/ismej.2016.150.

Sylvester, J. T., S. K. R. Karnati, B. A. Dehority, M. Morrison, G. L. Smith, N. R. St-Pierre, and J. L. Firkins. 2009. Rumen ciliated protozoa decrease generation time and adjust $18 \mathrm{~S}$ ribosomal DNA copies to adapt to decreased transfer interval, starvation, and monensin. J. Dairy Sci. 92:256-269.

Thoetkiattikul, H., W. Mhuantong, T. Laothanachareon, S. Tangphatsornruang, V. Pattarajinda, L. Eurwilaichitr, and V. Champreda. 2013. Comparative analysis of microbial profiles in cow rumen fed with different dietary fiber by tagged $16 \mathrm{~S}$ rRNA gene pyrosequencing. Curr. Microbiol. 67:130-137.

Valdez-Vazquez, I., and H. M. Poggi-Varaldo. 2009. Hydrogen production by fermentative consortia. Renew. Sustain. Energy Rev. 13:1000-1013.

Vos, P., G. Garrity, D. Jones, N. R. Krieg, W. Ludwig, F. A. Rainey, K.-H. Schleifer, and W. Whitman. 2009. Bergey's Manual of Systematic Bacteriology: Volume 3: The Firmicutes. Vol. 3. Springer Science \& Business Media, New York, NY.

Watanabe, Y., R. Suzuki, S. Koike, K. Nagashima, M. Mochizuki, R. J. Forster, and Y. Kobayashi. 2010. In vitro evaluation of cashew nut shell liquid as a methane-inhibiting and propionate-enhancing agent for ruminants. J. Dairy Sci. 93:5258-5267.

Weimer, P. J. 2015. Redundancy, resilience, and host specificity of the ruminal microbiota: Implications for engineering improved ruminal fermentations. Front. Microbiol. 6:296.

Weimer, P. J., D. M. Stevenson, D. R. Mertens, and M. B. Hall. 2011. Fiber digestion, VFA production, and microbial population changes during in vitro ruminal fermentations of mixed rations by monensin-adapted and unadapted microbes. Anim. Feed Sci. Technol. 169:68-78.

Weimer, P. J., D. M. Stevenson, D. R. Mertens, and E. E. Thomas. 2008. Effect of monensin feeding and withdrawal on populations of individual bacterial species in the rumen of lactating dairy cows fed high-starch rations. Appl. Microbiol. Biotechnol. 80:135-145.

Whitman, W., M. Goodfellow, P. Kämpfer, H.-J. Busse, M. E. Trujillo, W. Ludwig, K.-i. Suzuki, and A. Parte. 2012. Bergey's Manual of Systematic Bacteriology: Volume 5: The Actinobacteria. Springer, New York, NY.

Wischer, G., J. Boguhn, H. Steingass, M. Schollenberger, K. Hartung, and M. Rodehutscord. 2013. Effect of monensin on in vitro fermentation of silages and microbial protein synthesis. Arch. Anim. Nutr. 67:219-234.

Yang, C. M., and J. B. Russell. 1993a. Effect of monensin on the specific activity of ammonia production by ruminal bacteria and disappearance of amino nitrogen from the rumen. Appl. Environ. Microbiol. 59:3250-3254.

Yang, C. M., and J. B. Russell. 1993b. The effect of monensin supplementation on ruminal ammonia accumulation in vivo and the numbers of amino acid-fermenting bacteria. J. Anim. Sci. 71:3470 3476 . 